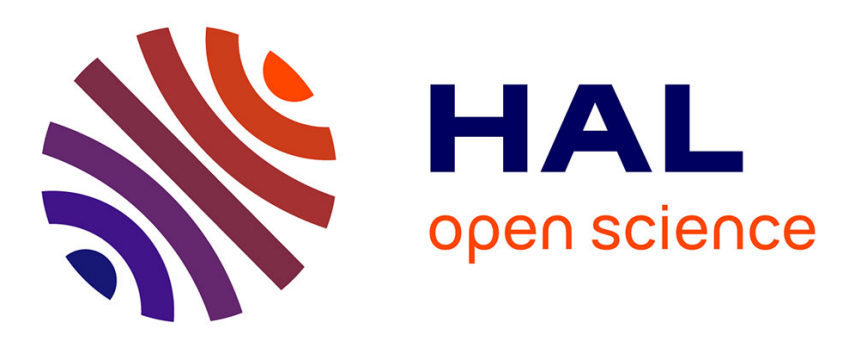

\title{
Imaging and therapeutic applications of persistent luminescence nanomaterials
}

Jianhua Liu, Thomas Lécuyer, Johanne Seguin, Nathalie Mignet, Daniel

Scherman, Bruno Viana, Cyrille Richard

\section{To cite this version:}

Jianhua Liu, Thomas Lécuyer, Johanne Seguin, Nathalie Mignet, Daniel Scherman, et al.. Imaging and therapeutic applications of persistent luminescence nanomaterials. Advanced Drug Delivery Reviews, 2019, 138, pp.193-210. 10.1016/j.addr.2018.10.015 . hal-02123130

\section{HAL Id: hal-02123130 \\ https://hal.science/hal-02123130}

Submitted on 18 Jun 2021

HAL is a multi-disciplinary open access archive for the deposit and dissemination of scientific research documents, whether they are published or not. The documents may come from teaching and research institutions in France or abroad, or from public or private research centers.
L'archive ouverte pluridisciplinaire HAL, est destinée au dépôt et à la diffusion de documents scientifiques de niveau recherche, publiés ou non, émanant des établissements d'enseignement et de recherche français ou étrangers, des laboratoires publics ou privés.

\section{(c)(1)}

Distributed under a Creative Commons Attribution| 4.0 International License 
Imaging and therapeutic applications of persistent luminescence nanomaterials

Jianhua Liu ${ }^{\mathrm{a}}$, Thomas Lécuyer ${ }^{\mathrm{a}}$, Johanne Séguin ${ }^{\mathrm{a}}$, Nathalie Mignet ${ }^{\mathrm{a}}$, Daniel Scherman ${ }^{\mathrm{a}}$, Bruno Viana $^{\text {b, }}$, Cyrille Richard ${ }^{\mathrm{a}, *}$

${ }^{a}$ Unité de Technologies Chimiques et Biologiques pour la Santé, CNRS UMR 8258; Inserm U 1022; Université Paris Descartes, Sorbonne Paris Cité, Faculté des Sciences Pharmaceutiques et Biologiques, 75006 Paris, France.

${ }^{\mathrm{b}}$ Chimie ParisTech, PSL University, CNRS, Institut de Recherche de Chimie Paris, 75005 Paris, France.

bruno.viana@chimieparistech.psl.eu

cyrille.richard@parisdescartes.fr 


\begin{abstract}
The development of probes for biomolecular imaging and diagnostics is a very active research area. Among the different imaging modalities, optics emerged since it is a noninvasive and cheap imaging technique allowing real time imaging. In vitro, this technique is very useful however in vivo, fluorescence suffers from low signal-to-noise ratio due to tissue autofluorescence under constant excitation. To address this limitation, novel types of optical nanoprobes are actually being developed and among them, persistent luminescence nanoparticles (PLNPs), with long lasting near-infrared (NIR) luminescence capability, allows doing optical imaging without constant excitation and so without autofluorescence. This review will begin by introducing the physical phenomenon associated to the long luminescence decay of such nanoprobes, from minutes to hours after ceasing the excitation. Then we will show how this property can be used to develop in vivo imaging probes and also more recently nanotheranostic agents. Finally, preliminary data on their biocompatibility will be mentioned and we will conclude by envisioning on the future applications and improvements of such nanomaterials.
\end{abstract}

Keywords: Persistent luminescence, nanoparticles, surface coating, physical stimulus, in vivo, imaging, therapy, nanotheranostics. 


\section{Introduction}

The possibility to detect and diagnose diseases earlier than with current imaging methods causes a drastic increase of interest in imaging technologies. A noninvasive, cheap imaging technique, comfortable, portable, highly sensitive and that allows real-time imaging is still to be developed. Among the different existing imaging modalities, optical imaging has largely grown in recent years. This technique is highly complementary to others, such as X-rays or magnetic resonance imaging, since it allows acquisition of data at high speeds, allowing the visualization of biological processes or events in real time. ${ }^{1}$ For that purpose, fluorescent probes are often used in order to enable the study of biological processes. ${ }^{2}$ Among these probes, semiconductor quantum dots (QDs) exhibiting fluorescence optical properties have emerged as a class of nanoparticles for bioimaging and diagnostics. These crystals are highly fluorescent, allowing their use for in vitro and in vivo applications. ${ }^{3,4}$ Upconversion nanoparticles (UCNPs) doped with rare earth elements, are another type of nanoprobes which emerged for diagnostic applications. ${ }^{5}$ UCNPs convert near-infrared (NIR) photons to higher energy (visible or ultraviolet) photons. ${ }^{6}$ The NIR excitation light of UCNPs (970$980 \mathrm{~nm}$ for trivalent ytterbium or around $810 \mathrm{~nm}$ for neodynium) fall into the biological window where light penetration in tissue occurs with minimal absorption and scattering. The phenomenon of upconversion leads to imaging living organisms with lower background autofluorescence in comparison with conventional fluorescent labels. ${ }^{7}$ However, despite these advantages, optical imaging is limited because photons are scattered and absorbed by the tissues. The penetration depth of photons inside a tissue depends both on the type of tissue, ${ }^{8}$ and on the wavelength $(\lambda)$ used. Scattering drastically decreases when $\lambda$ increases in the so-call tissue transparency window. ${ }^{9}$ In vivo imaging using fluorescent probes gave interesting results in clinical trials, for example for the detection of breast cancer, for the delimitation of tumor during surgery ${ }^{10}$ and for diagnosis of cancer by endoscopy. ${ }^{11,12}$ But as already mentioned above this technique is limited by factors such as tissue autofluorescence, ${ }^{13}$ which greatly limits the quality of images, especially when working with small amount of fluorescent probe. A review of the state of the art for semiconductors QDs, UCNPs and first results with PLNPs was recently reported. ${ }^{14}$ Persistent luminescence is a particular optical phenomenon in which luminescent materials keep emitting light a long time after the excitation is stopped. This phenomenon has intrigued people since several centuries. ${ }^{15}$ As this property occurs in inorganic materials when the excitation has been stopped, this is sometimes compared to the bioluminescence mechanism observed in some animals, such as fireflies and jellyfishes. ${ }^{16}$ Since a decade, researches are in progress to use this property for the development of in vivo optical probes. The main advantage when using this approach for in vivo imaging is the total absence of background signal, as represented on Fig. 1 (left). This is in total opposition to what is classically obtained when using most fluorescent probes, with short luminescence decay, in the order of nanoseconds, such as cyanine or QDs (Fig. 1, middle or right respectively) for which autofluorescence signal is very high. ${ }^{17}$

This review manuscript will present this particular optical characteristic of persistent luminescence (section 2) and will report its application in biology, for both imaging (section 3) and therapy (section 4). 


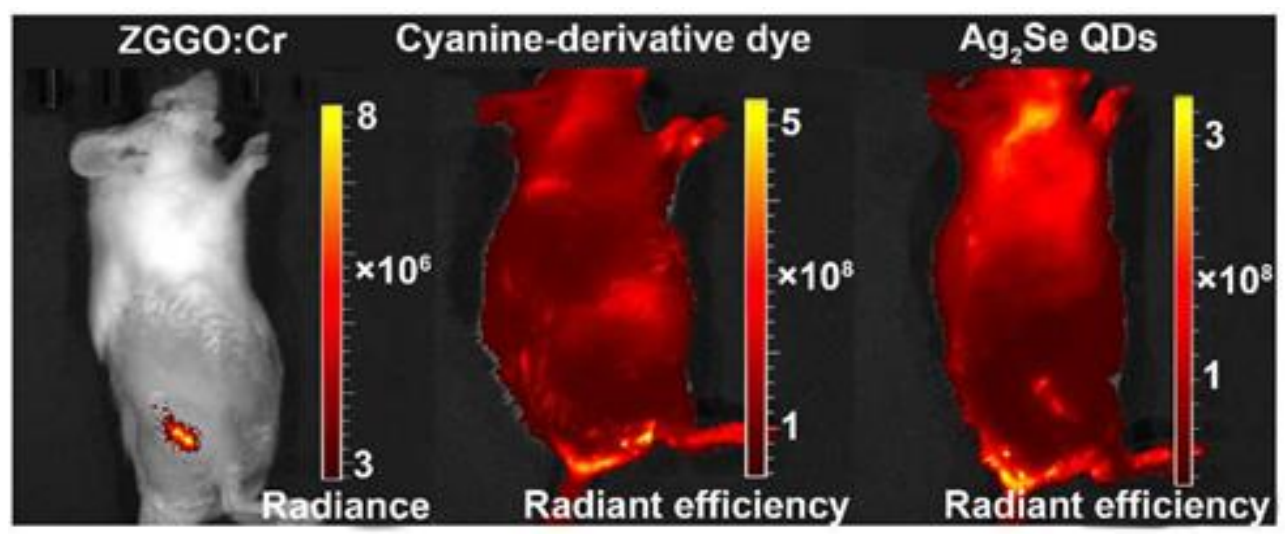

Fig. 1. Comparis on of optical in vivo imaging using either persistent luminescence nanoparticles, ZGGO:Cr (left) or conventional fluorescent probes, Cyanine or QDs (middle and right) [17].

2. Main characteristics of persistent luminescence materials

Unlike fluorescent probes that emit light for a very short time, a few nanoseconds after excitation, persistent luminescence materials can store the excitation energy into traps or defects under irradiation (Fig. 2). Then, when the excitation is stopped, persistent luminescence is controlled by the slow liberation of trapped charged carriers at room temperature, mainly by a simple thermal de-excitation process. In such conditions, the luminescence which results from traps and holes recombination at the luminescent center can last for several minutes to hours after removal of the excitation source. ${ }^{18,19}$ Fig. 2 presents the simplify energy levels of luminescence center and traps responsible of the persistent luminescence. In this figure, the same cation is presented as recombination and excitation centers and trapping and detrapping can occur via the conduction band ( $\mathrm{CB}$, dashed black lines) or by direct interaction (dashed blue line). Only traps at energy depths in the bandgap ranging between 0.5 to $1 \mathrm{eV}$ are effective for direct persistent luminescence while deeper traps $(\mathrm{E}>1 \mathrm{eV})$ can be activated by photostimulation or X-ray stimulation, as presented later in this review paper.

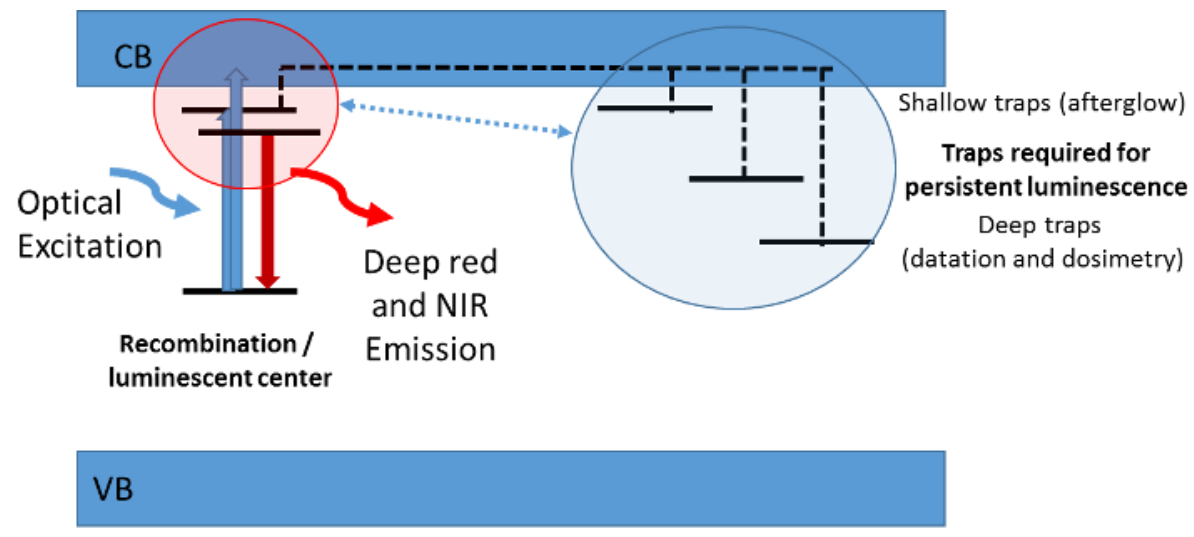

Fig. 2. Schematic of the energy levels and traps involved in the persistent luminescence mechanisms.

The main applications of this phenomenon, we are used in everyday life, are emergency signs that can be used in case of power failure. This is one of the main applications of persistent phosphors, but others have been reported in night vision such as in watch dials (when radioactive elements were banned more than twenty years ago), decorative objects and toys. Recently our groups have proposed 
the application of this phenomenon for in vivo optical imaging on small animals. This will be the topic of this review article.

For the materials concerned with persistent luminescence properties, lots of compositions have been tested in the literature with various successes (Table 1). More than two hundred combinations of host materials and activator ions have been depicted in which rare earth (RE) and metal transition (MT) cations have been widely used as dopants to enhance the persistent luminescence properties. The main nanoparticles developed for bioimaging applications, later called PLNPs as an acronym for Persistent Luminescence NanoParticles, using metal transition cations and rare-earth cations for deep red/near infrared emission are reported in Table 1. 
Table 1. Main materials used with metal transition (MT) cations and RE (rare earth) cations for red/near infrared persistent emission and bio-applications.

\begin{tabular}{|c|c|c|c|}
\hline Hosts & Dopants & $\begin{array}{l}\text { Comments and applications } \\
\text { in bio-imaging }\end{array}$ & Year $^{\text {Ref }}$ \\
\hline $\mathrm{Gd}_{2} \mathrm{O}_{2} \mathrm{~S}$ & $\mathrm{Eu}^{3+}, \mathrm{Mg}^{2+}, \mathrm{Ti}^{4+}$ & $\begin{array}{l}\text { NPs regular shape, bimodality optical / } \\
\text { MRI }\end{array}$ & $2015^{20}$ \\
\hline $\begin{array}{l}\mathrm{Ca}_{3}\left(\mathrm{PO}_{4}\right)_{2} / \\
\text { Hydroxy apatite }\end{array}$ & $\mathrm{Mn}^{2+}, \mathrm{Tb}^{3+}, \mathrm{Dy}^{3+}$ & $\begin{array}{l}\text { Fully biocompatible, NPs and in vivo } \\
\text { imaging }\end{array}$ & $2015^{20}$ \\
\hline $\mathrm{Ca}_{2} \mathrm{Si}_{5} \mathrm{~N}_{8}$ & $\mathrm{Eu}^{2+}, \mathrm{Tm}^{3+}$ & Bioimaging applications & $2012^{21}$ \\
\hline $\mathrm{SrAl}_{2} \mathrm{O}_{4}$ & $\mathrm{Eu}^{2+}, \mathrm{Dy}^{3+}$ & $\begin{array}{l}\text { NPs, functionalization, Bioimaging } \\
\text { applications, green emission }\end{array}$ & $2014,2018^{22}$ \\
\hline $\begin{array}{l}\mathrm{Ca}_{0.2} \mathrm{Zn}_{0.9} \mathrm{Mg}_{0.9} \mathrm{Si}_{2} \mathrm{O}_{6} \\
\mathrm{Ca}_{1.86} \mathrm{Mg}_{0.14} \mathrm{ZnSi}_{2} \mathrm{O}_{7}\end{array}$ & $\begin{array}{l}\mathrm{Mn}^{2+}, \mathrm{Eu}^{2+}, \mathrm{Dy}^{3+} \\
\mathrm{Eu}^{2+}, \mathrm{Dy}^{3+}\end{array}$ & $\begin{array}{l}\text { NPs, functionalization, pioneer work for } \\
\text { bio-imaging: cancer cells imaging, cell } \\
\text { targeting } \\
\text { FRET and various bio-sensing } \\
\text { applications }\end{array}$ & $\begin{array}{c}2007,{ }^{25} 2011,2012 \\
2018^{24}\end{array}$ \\
\hline $\mathrm{CaMgSi}_{2} \mathrm{O}_{6}$ & $\mathrm{Mn}^{2+}, \mathrm{Eu}^{2+}, \mathrm{Pr}^{3+}$ & NPs, functionalization, bio-imaging & $2011^{25}$ \\
\hline $\mathrm{MAlO}_{3}(\mathrm{M}=\mathrm{La}, \mathrm{Gd})$ & $\mathrm{Mn}^{4+} / \mathrm{Ge}^{4+}$ & Bio-imaging in pork tissue & $2016^{26}$ \\
\hline $\mathrm{GdAlO}_{3}$ & $\begin{array}{l}\mathrm{Mn}^{4+}, \mathrm{Ge}^{4+} @ \mathrm{Au} \\
\mathrm{Sm}^{3+}, \mathrm{Cr}^{3+}\end{array}$ & $\begin{array}{l}\text { Trimodality imaging } \\
\text { Optical and magnetic dual mode imaging }\end{array}$ & $\begin{array}{l}2016^{26} \\
2018^{27}\end{array}$ \\
\hline $\mathrm{ZnGa}_{2} \mathrm{O}_{4}$ & $\mathrm{Cr}^{3+}$ & $\begin{array}{l}\text { NPs, functionalization, bio-imaging } \\
\text { (cancer cells imaging), Cell targeting, } \\
\text { cy totoxicity, visible Light NIR } \\
\text { photostimulation, } \\
\text { X-rays activation } \\
\text { Oral administration \& breast cancer } \\
\text { imaging } \\
\text { Toxicology analy sis } \\
\text { Protobiotic analysis }\end{array}$ & $\begin{array}{c}2013^{29} \\
2018^{30} \\
2018^{31} \\
2017^{32} \\
2018^{33}\end{array}$ \\
\hline $\mathrm{ZnGa}_{2} \mathrm{O}_{4}$ in hollow cavity & $\mathrm{Cr}^{3+}$ & Photodynamic therapies & $2018^{34}$ \\
\hline $\mathrm{ZnGa}_{2} \mathrm{O}_{4}$ & $\mathrm{Cr}^{3+}, \mathrm{Gd}^{3+}$ & $\begin{array}{l}\text { NPs, functionalization, bimodality } \\
\text { optical/NMR imaging }\end{array}$ & $2015^{35}$ \\
\hline $\begin{array}{l}\mathrm{ZnGa}_{2} \mathrm{O}_{4} / \mathrm{SiO}_{2} \\
\mathrm{ZnGa}_{2} \mathrm{O}_{4} / \mathrm{Fe}_{2} \mathrm{O}_{3} \\
\mathrm{ZGOCS} @ \mathrm{~m}-\mathrm{SiO}_{2} @ \mathrm{Gd}_{2} \mathrm{O}_{3} \\
\end{array}$ & $\begin{array}{l}\mathrm{Cr}^{3+} \\
\mathrm{Cr}^{3+} \\
\mathrm{Cr}^{3+}\end{array}$ & $\begin{array}{l}\text { Core-shell structure, drug delivery } \\
\text { Cell labelling and magnetic vectorization, } \\
\text { multimodal nanoprobes }\end{array}$ & $\begin{array}{c}2014^{36} \\
2015,^{37} 2018^{38} \\
2017^{39} \\
\end{array}$ \\
\hline $\mathrm{Zn}_{1.1} \mathrm{Ga}_{1.8} \mathrm{Ge}_{0.1} \mathrm{O}_{4} / \mathrm{SiO}_{2}$ & $\mathrm{Cr}^{3+}, \mathrm{Eu}^{3+}$ & NPs, core-shell structure, drug delivery & $2015^{40}$ \\
\hline $\mathrm{Zn}_{3} \mathrm{Ga}_{2} \mathrm{Ge}_{2} \mathrm{O}_{10}$ & $\mathrm{Cr}^{5+}$ & $\begin{array}{l}\text { Imaging of pork tissue, Photostimulation, } \\
\text { cy totoxicity }\end{array}$ & $2014^{41}$ \\
\hline $\mathrm{Zn}_{1.1} \mathrm{Ga}_{1.8} \mathrm{Ge}_{0.1} \mathrm{O}_{4} @ \mathrm{SiO}_{2}$ & $\mathrm{Cr}^{3+}$ & Bio-imaging and drug delivery & $2018^{42}$ \\
\hline $\mathrm{Zn}_{1.25} \mathrm{Ga}_{1.5} \mathrm{Ge}_{0.25} \mathrm{O}_{4}$ & $\mathrm{Cr}^{3+}, \mathrm{Yb}^{3+}, \mathrm{Er}^{3+}$ & $\begin{array}{l}\text { Metastasis tracking and chemo- } \\
\text { photodynamic therapy }\end{array}$ & $2018^{43}$ \\
\hline $\mathrm{Zn}_{1.1} \mathrm{Ga}_{1.8} \mathrm{Ge}_{0.1} \mathrm{O}_{4}$ & $\mathrm{Cr}^{3+}$ & Nanothermometry & $2017^{44}$ \\
\hline $\mathrm{Zn}_{3} \mathrm{Ga}_{2} \mathrm{Sn}_{1} \mathrm{O}_{10}$ & $\mathrm{Cr}^{3+}$ & Imaging of goldfish & $2014^{45}$ \\
\hline $\begin{array}{l}\mathrm{Zn}_{2.94} \mathrm{Ga}_{1.96} \mathrm{Ge}_{2} \mathrm{O}_{10} \\
\mathrm{Zn}_{3} \mathrm{Ga}_{2} \mathrm{Ge}_{2} \mathrm{O}_{10}\end{array}$ & $\begin{array}{l}\mathrm{Cr}^{3+}, \mathrm{Pr}^{3+} \\
\mathrm{Cr}^{3+}\end{array}$ & $\begin{array}{l}\text { NPs, functionalization } \\
\text { Recognition of breast cancer cells }\end{array}$ & $\begin{array}{l}2013^{40} \\
2015^{47}\end{array}$ \\
\hline $\mathrm{Zn}_{3} \mathrm{Ga}_{2} \mathrm{GeO}_{8}$ & $\mathrm{Cr}^{3+}, \mathrm{Yb}^{3+}, \mathrm{Er}^{3+}$ & Upconversion & $2014^{48}$ \\
\hline $\mathrm{LiGa}_{5} \mathrm{O}_{8}$ & $\mathrm{Cr}^{3+} / \mathrm{PEG}-\mathrm{OCH}_{3}$ & $\begin{array}{l}\text { NPs, functionalization, bio-imaging, } \\
\text { Visible light stimulation, photostimulation }\end{array}$ & $2013,{ }^{49} 2014^{50}$ \\
\hline $\begin{array}{l}\mathrm{Ca}_{3} \mathrm{Ga}_{2} \mathrm{Ge}_{3} \mathrm{O}_{12} \\
\mathrm{~m}-\mathrm{SiO}_{2} @ \mathrm{Gd}_{3} \mathrm{Ga}_{5} \mathrm{O}_{12}\end{array}$ & $\begin{array}{l}\mathrm{Cr}^{3+}, \mathrm{Yb}^{3+}, \mathrm{Tm}^{3+} \\
\mathrm{Pr}^{3+}, \mathrm{Yb}^{3+} \\
\mathrm{Cr}^{3+}, \mathrm{Nd}^{3+}\end{array}$ & $\begin{array}{l}\text { NIR stimulation, up conversion } \\
\text { In vivo imaging } \\
\text { multimodal imaging and cancer therapy }\end{array}$ & $\begin{array}{l}2014^{51} \\
2017^{52} \\
2018^{53}\end{array}$ \\
\hline $\mathrm{Sr}_{2} \mathrm{SnO}_{4}$ & $\mathrm{Nd}^{3+}$ & Finger image & $2014^{54}$ \\
\hline $\begin{array}{l}\mathrm{SiO}_{2} / \mathrm{CaM} \mathrm{gSi}_{2} \mathrm{O}_{6} \\
\text { YAGG (garnet) }\end{array}$ & $\begin{array}{l}\mathrm{Eu}^{2+}, \mathrm{Pr}^{3+}, \mathrm{Mn}^{2+} \\
\mathrm{Er}^{3+} \mathrm{Cr}^{3+}\end{array}$ & $\begin{array}{l}\text { Bio-imaging, intraperitoneal injection } \\
\text { Photostimulation imaging of pork tissue } \\
\text { Imaging in the second biological window }\end{array}$ & $2014^{55}$ \\
\hline $\mathrm{NaYF}_{4}+\mathrm{SrAl}_{2} \mathrm{O}_{4}$ & $\begin{array}{l}\mathrm{Yb}^{3+}, \mathrm{Tm}^{3+} \\
\mathrm{Eu}^{2+}, \mathrm{Dy}^{3+}\end{array}$ & Upconversion \& photodynamic therapy & $2018^{57}$ \\
\hline $\mathrm{Sr}_{2} \mathrm{MgSi}_{2} \mathrm{O}_{7}$ & $\mathrm{Eu}^{2+1 / 3+}, \mathrm{Dy}^{3+}$ & $\begin{array}{l}\text { Photodynamic activation } \\
\text { Visualization of abdominal inflammation }\end{array}$ & $\begin{array}{l}2016^{58} \\
2018^{59}\end{array}$ \\
\hline $\begin{array}{l}\mathrm{La}_{3} \mathrm{Ga}_{5} \mathrm{GeO}_{14} \\
\text { (vancomycin) }\end{array} \mathrm{SiO}_{2} @ \mathrm{Van}$ & $\mathrm{Cr}^{3+}, \mathrm{Zn}^{2+}$ & $\begin{array}{l}\text { Bio-imaging-guided in vivo \& drug } \\
\text { delivery }\end{array}$ & $2018^{60}$ \\
\hline $\mathrm{CaTiO}_{3}$ & $\mathrm{Pr}^{3+}, \mathrm{Yb}^{3+}, \mathrm{Tm}^{3+}$ & $\begin{array}{l}\text { Upconverting and guided photothermal } \\
\text { therapy }\end{array}$ & $2017^{61}$ \\
\hline $\mathrm{ZnSn}_{2} \mathrm{O}_{4}$ & $\mathrm{Cr}^{3+}, \mathrm{Eu}^{3+}$ & Cellular and deep tissue imaging & $2017^{62}$ \\
\hline
\end{tabular}


The reader could further see reviews and book chapter on the persistent luminescence topic. ${ }^{64,65,66}$ Concerning bioimaging and in vivo applications, the past ten years have witnessed several major advances to establish deep red/near-infrared emitting PLNPs as a novel approach for real-time in vivo imaging in small animal. ${ }^{67,68,69}$. For that application both size and emission wavelength should be controlled (see section 2 and 3).

\subsection{Persistent luminescence mechanisms}

The physics related to the phenomenon of persistent luminescence is not simple and lots of research has been going on for years to understand it. For the trapping process which is the primary very important step, two kinds of traps are envisioned: (i) extrinsic defects obtained by adding dopants during the synthesis of the material or (ii) intrinsic defects which correspond either to anions vacancies (such as oxygen) or cations deficiencies. ${ }^{70,71}$ In some compounds, antisite defects corresponding to cationic exchanges are very likely, varying some chemical bonds and creating low energy traps (shallow traps) in the conduction band (see Fig. 2). For example, authors have proposed the existence of antisite defects near $\mathrm{Cr}^{3+}$ ions in order to explain the persistent luminescence of the zinc gallate $\left(\mathrm{ZnGa}_{2} \mathrm{O}_{4}, \mathrm{ZGO}\right)$ spinel host used in section $3 .^{72,73,74,75}$ It must be also emphasized that thermal annealing with or without reducing atmosphere can create or increase the number of intrinsic traps such as oxygen vacancies leading to persistent luminescence. ${ }^{76,77}$

\subsection{Traps and co-doping}

Co-doping (extrinsic defect) is another strategy largely used to enhance the persistent luminescence, for example by co-doping the material with one or two lanthanides cations. For instance, $\mathrm{Dy}^{3+}$ was used as electrons trap in the first hybrid enstatite/diopside silicate developed for proof of concept of in vivo bioimaging with PLNPs. ${ }^{23}$ Later it appeared that co-doping with $\operatorname{Pr}^{3+}$ was indeed better when the diopside bandgap was considered. ${ }^{25}$ The variation of traps depths strongly depend of the couple host/dopant and corresponds to a so-call bandgap engineering as introduced in previous works, ${ }^{78,79}$ with the prediction of the energy level diagram. ${ }^{80,81}$ Such bandgap engineering was proposed in various hosts used for persistent luminescence but was also tested with success for others photonic applications such as scintillation and lighting. ${ }^{82}$ To improve the persistent luminescence performance, it is possible to vary the position of the conduction band and the traps depth by varying the composition, or by playing with cationic and anionic substitutions or by a careful choice of the doping cation for an optimal couple composition/dopant.

To go in deeper understanding, knowledge of the energy formation of defects, defects stability and defects energy position are required, through band structure and defects calculations. ${ }^{83}$ Several spectroscopic techniques have been used to study the persistent luminescence mechanism such as: optical, Electron Paramagnetic Resonance (EPR) to control the origin and defects intensity, ${ }^{84} \mathrm{X}$-rays spectroscopies to give insight to the mechanism ${ }^{85}$ thermoluminescence and photoconductivity ${ }^{86,87}$ to measure the traps depth. ${ }^{88}$ In the case of electrons traps and holes traps, ${ }^{89}$ the stored charges can be released by various processes, as presented in the following part of this review, such as thermal, ${ }^{90}$ optical $^{91}$ or others physical stimulations, ${ }^{92}$ resulting in stimulated emissions from the active recombination centers.

\subsection{Excitation sources (physical stimuli) used to charge/discharge nanoprobes}

The first generation of PLNPs was only excitable (charged) ex vivo using UV light before its injection, ${ }^{23}$ allowing in vivo optical imaging (see section 3 ). This procedure has a limit for some applications such as the visualization of accumulation of the probe within tumors which usually 
requires several hours after injection. ${ }^{93}$ This was too long compared to the duration of persistent luminescence, which doesn't go beyond one hour in vivo.

To overcome this major restriction, developments of new materials and new excitation modalities have been undertaken. First, efforts to optimize compositions and enhanced optical characteristics have been made. In that sense, compounds based on new host materials such as gallate and gallo-germanate spinels have attracted great attention, mainly due to their bright deep persistent luminescence when doped with trivalent chromium $\left(\mathrm{Cr}^{3+}\right)$ and excite with UV compared to previously used silicate nanoprobes (see section 3). However, the main breakthrough was the possibility to reexcite the persistent luminescence material at lower energy in the biological window, through the animal body, allowing longer time observations. For that purpose, new modalities have been proposed, as seen in Figure 3.

This figure summarizes the various approaches that can be followed for long term in vivo imaging with persistent luminescent nanoparticles. Indeed, PLNPs dispersed in biological buffer, such as PBS or glucose, can be pre-excited in a syringe ex situ, injected into small animal and then the persistent luminescence signal emitted by the probe can be collected by a photon-counting system (step 1, Fig. 3). Depending on their composition, some PLNPs can be excited or re-excited in vivo through the animal body (step 2, Fig. 3). This way of proceeding allows the recovery of persistent luminescence signal whenever wanted. The efficiency is however weaker than for the persistent luminescence under UV excitation (step 1) but it is indeed enough to detect and localize the probe in vivo over long time. Furthermore for some persistent luminescent nanoprobes, when deeper traps are observed in the thermoluminescence spectra, such as in garnet or spinel hosts (Table 1), deep-red persistent emission can be activated or stimulated using near infrared light, in such a process we are talking about photostimulated persistent luminescence (PSPL). ${ }^{94,95,96}$ Charging of the persistent phosphors is also possible through second order effects. ${ }^{97}$ The photostimulation capability of several materials is widely reported and researchers have focused their attention on the $\mathrm{Cr}^{3+}$ doped samples. This technique is highly used for UV dosimetry, as well as in geology and archeology for dating. ${ }^{98}$ One can adjust the depth of the traps responsible for the persistent luminescence and therefore control carefully the composition. In that case, the release of the traps and thus the emission of light could be started at the convenience of the user, using a red/near infrared LED for instance which will be in the best transparency range. The first preliminary tests carried out have shown the originality and feasibility of this new modality. ${ }^{99}$ 

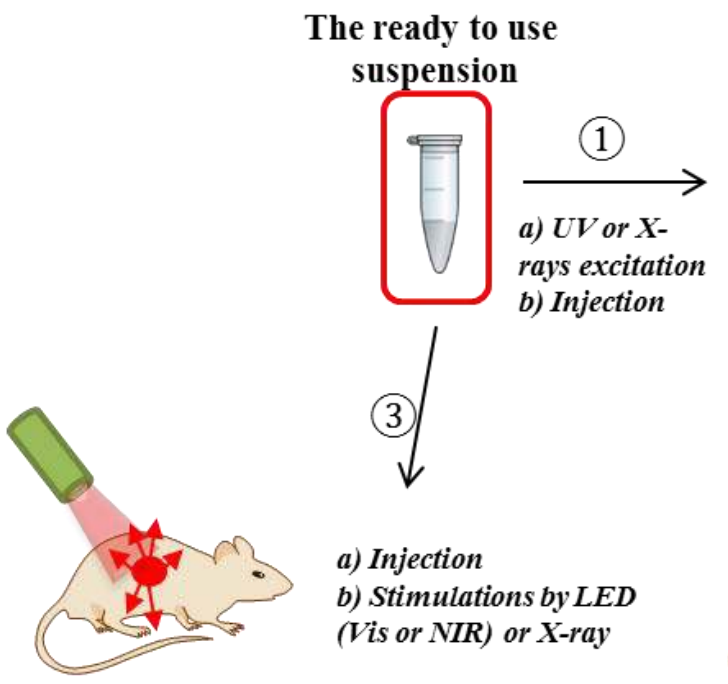

\section{Emission of the PLNP}

(Vis or NIR) or X-ray

Fig 3: Different physical strategies (stimuli) allowing performing in vivo optical imaging with persistent luminescence nanoparticles (PLNPs). (1) Ex situ excitation of a suspension of nanoparticles with UV followed by tail vein injection and optical imaging using a photon counting camera. (2) Once the in vivo persistent luminescence signal has completely disappeared, some PLNPs can give further activated either by photo or X-rays stimulations. (3) Some PLNPs can be directly excited in the animal body using visible, near infrared or X-rays photons without preliminary ex-situ excitation. [14]

The energy needed for electron detrapping vary from red to NIR (LED or laser sources). ${ }^{100,101,102}$ However, in vivo excitation is hindered by its limited penetration in tissue even in the near infrared. An alternative way is to use other excitation source, such as X-ray. Compared to the traditional excitation source (UV/visible/NIR), X-ray has a number of advantages such as weaker scattering and deeper penetration in tissues, as well as simplified image reconstruction in tomography. ${ }^{103}$ This allows achieving deeper tissue and higher sensitivity imaging with better spatial resolution. With these additional excitation pathways, the charges can be released from deep traps and redistributed to shallow traps in order to produce a persistent luminescence signal.$^{104,105}$

The following section 3 and 4 present several examples from the literature using different physical stimuli discussed previously (UV, visible, photostimulation, NIR, X-rays) to excite PLNPs for in vivo bioimaging or therapy.

\section{In vivo bioimaging}

The main features that a probe has to fulfill for in vivo applications are the following: (i) it must be prepared as nanoparticles (PLNPs with size $<100 \mathrm{~nm}$ ), (ii) with an intensive emission extending in the deep red toward the near infrared range corresponding to the tissue window transparency, ${ }^{106}$ (iii) efficient functionalization, ${ }^{107,108,109}$ (iv) stability in biological media, ${ }^{110}$ (v) persistent emission. These points are the reasons why applications of persistent phosphors for bio-applications were little investigated at the beginning of the development of the persistent phosphors in 1996 and the investigation started later in 2007, after our pioneer paper was published. ${ }^{23}$ Since that time, several materials have been developed for imaging applications (see review papers [24, 68] and Table 1). Notice that at first all the researches were focused in the deep-red range (high transmission range of 
the living tissue) where the silicon detectors of the cameras also reach their maximal sensitivity. But very recently, researchers expend the range to the second and third biological windows (BW-II and BW-III) even if the results are still very preliminary. ${ }^{111}$ For the development of new nanomaterials with long persistent luminescence for bio-applications, we must have in mind that different strategies are developed to get small size PLNPs but also with the maximum of defects at the origin of the persistent luminescence (section 2). For this purpose, hydrothermal, solvothermal, sol-gel, coprecipitation and microwaves methods have been developed. ${ }^{69}$ Finally, surface functionalization is required to make these probes biocompatible in order to be used for in vivo applications. This section presents a selection of works developed in our group and latest works by colleagues concerning the use of persistent luminescence nanoparticles as efficient nanoprobes for in vivo imaging. ${ }^{12}$

\subsection{Proof of concept: UV excitable nanoprobes}

The first article reporting the use of persistent luminescence nanoparticles (PLNPs) for optical in vivo imaging was published in 2007 by Scherman and co-workers. ${ }^{23}$ As discussed previously, to be used in vivo, the probe must have a nanometric size and must emit radiation in the biological window $(>650$ $\mathrm{nm})$. In their work, the authors prepared a silicate enriched with $\mathrm{RE}\left(\mathrm{Eu}^{2+}, \mathrm{Dy}^{3+}\right)$ and MT: $\left(\mathrm{Mn}^{2+}\right)$. This material has the characteristics for the envisioned application: excitation of $\mathrm{Eu}^{2+}$ with $\mathrm{UV}$ light creates charges stored by electron traps $\left(\mathrm{Dy}^{3+}\right)$ and after thermal activation (by the animal body), persistent luminescence signal at $700 \mathrm{~nm}$ occurs due to recombination of charges at the emission center $\left(\mathrm{Mn}^{2+}\right)$ (Fig. 4A-B). ${ }^{113}$ The long lasting luminescence of this material, several hours after excitation (Fig. 4C) has been used by the authors in vivo. Thanks to the persistent luminescence signal, the authors proposed an alternative procedure to perform in vivo imaging (Fig. 4D). Unlike what is classically done with fluorescent probes which are excited in the animal body at the same time as the signal is recorded, suspension of PLNPs dispersed in physiological serum is excited ex vivo, outside the animal body, with a UV light, then the excited probe is injected into the mouse and the photons emitted are captured by a sensitive camera (Fig. 4D-E). In such conditions, in vivo imaging without any background (without any autofluorescence signal) can be performed for about 30 min to 1 hour (Fig $4 \mathrm{E})$. 

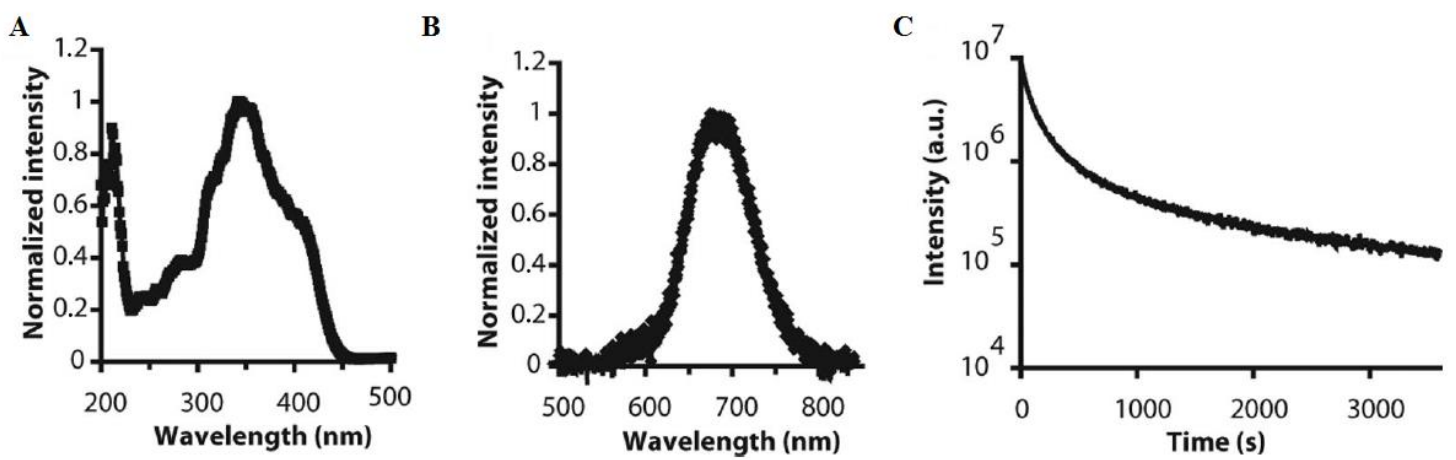

D

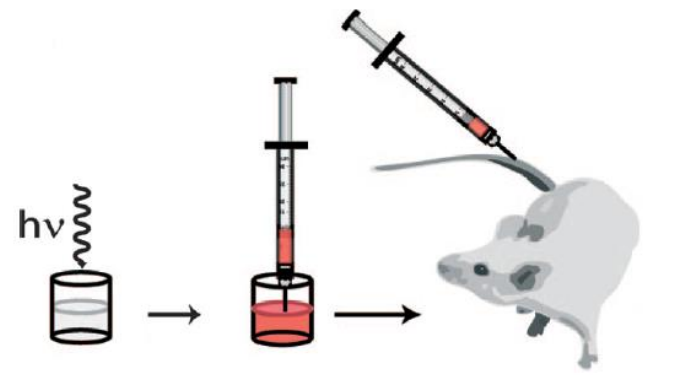

$\mathbf{E}$

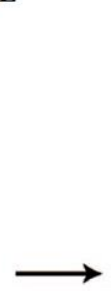

CMSO:Eu,Dy,Mn

\section{CMSO:Eu,Pr,Mn}
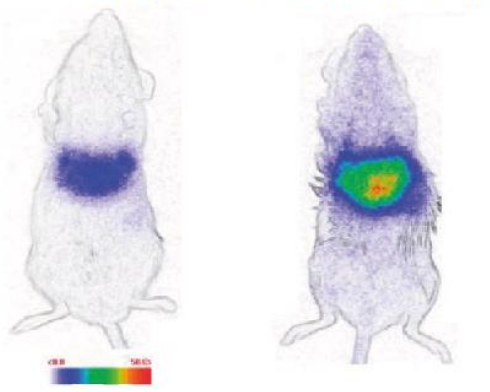

Fig. 4. In vivo imaging using the first generation of PLNPs. (a-c) Optical properties of silicate-based PLNPs. (d) Principle of in vivo imaging using PLNPs. (e) In vivo persistent luminescence signals obtained using a Biospace photon-counting camera and bioluminescence acquisition mode [23,25]

This was the first example showing that persistent luminescence nanoprobes could be used in small animal and detected without any background signal. With this first generation of PLNPs, in vivo imaging could be done for about $1 \mathrm{~h}$, luminescence intensity varying with the size of nanoprobes. ${ }^{65}$ This may be sufficient for some applications, but for others it can be necessary to do imaging for longer time. For that purpose, as discussed in section 2, a possibility was to change the nature of the electron traps, to favor both the trapping and the electron detrapping at the animal body temperature. For that purpose, the same research group synthesized other silicates in which they replaced the electrons trap of the first synthetized nanomaterial (i.e $\mathrm{Dy}^{3+}$ ) by other $\mathrm{RE}$ ions such as $\mathrm{Nd}^{3+}, \mathrm{Pr}^{3+}$ or $\mathrm{Ce}^{3+}$. Among these, they found that the silicate doped with $\mathrm{Pr}^{3+}$ was 5 times more efficient in term of luminescence intensity and decay, allowing doing imaging for longer time, about 3 hours after UV excitation and injection (Fig. 4E, right). ${ }^{25114,115,116}$

In 2012, Smet and co-workers ${ }^{21}$ proposed an alternative solution to do in vivo experiments with other PLNPs using a nitridosilicate matrix $\left(\mathrm{Ca}_{2} \mathrm{Si}_{5} \mathrm{~N}_{8}\right)$ doped with $\mathrm{Eu}^{2+}$ and $\mathrm{Tm}^{3+}$ as RE elements. In that case $\mathrm{Tm}^{3+}$ was the electrons trap and $\mathrm{Eu}^{2+}$ both activator and emitting center. The authors reported that this material could emit persistent luminescence light at $640 \mathrm{~nm}$ (BW-I) after UV excitation and they have evaluated its efficacy in vivo. However, in vivo, this material is not more efficient than the previous one in term of luminescence intensity and decay time. However, the main point to emphasize here is that these first examples highlighted the possibility of using persistent luminescence nanoprobes in vivo, as alternatives to conventional fluorescence probes in order to improve the diagnostic. However for long term imaging, their disadvantage was their excitation mode, using UV light, which limits their detection to a few hours after their excitation and injection to mice. However, these pioneer works opened the door to a new type of nanoprobes with oxides, nitrides and sulfide- 
based $\mathrm{NPs}^{117}$ and since that time, lots of bio-applications with various excitation modalities and compositions have been proposed, as seen in Table 1. Some of them will be detailed in the following part of the paper, using different physical methods (stimuli) to trigger the persistent luminescence.

\subsection{Strategies developed to perform longer time imaging}

\subsubsection{LED excitation}

To overcome the major restriction of the first generation of PLNPs, and to allow longer time imaging ( $>$ few hours), in 2014 Maldiney et al. have changed the matrix and have proposed the use of zinc gallium oxide doped with $\mathrm{Cr}^{3+}$. $28118,119,120$ As can be seen in Fig. 5, contrary to previous first generation silicates, this probe has three excitation bands, among which one being close to the tissue transparency window (Fig. 5A, hatched red rectangle). The authors synthesized $\mathrm{ZnGa}_{2} \mathrm{O}_{4}: \mathrm{Cr}(\mathrm{ZGO})$ in the form of nanoparticles and first characterized the powder. They observed a persistent luminescence decay signal after both UV (Fig. 5B, continuous line) and also after excitation with LEDs (Fig. 5B, dashed line). To evaluate the superiority of this probe in vivo, a suspension of this material dispersed into $5 \%$ glucose was injected into mice, and for the first time the authors have shown that the probe could be activated in vivo with orange/red light-emitting diodes (Fig. 5E). The authors have also shown that ex situ UV pre-excitation before LED re-activation was not necessary (Fig. 5C and 5H). In these conditions, there is no more time constraint and the probe can be observed in vivo when desired thanks to excitation with the LEDs (Fig. 5E-G). The authors successfully reported that such nanoprobes could be used in vivo, after a proper functionalization, to target and image tumors (Fig. 5G).

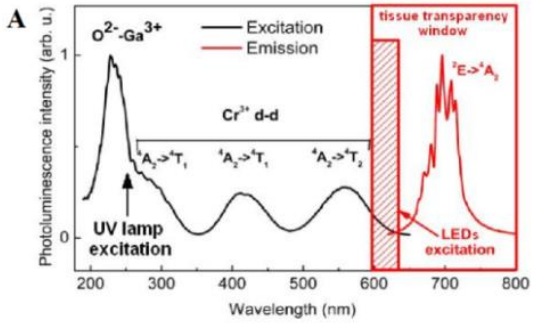

D

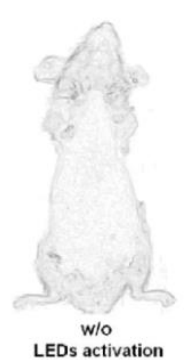

E

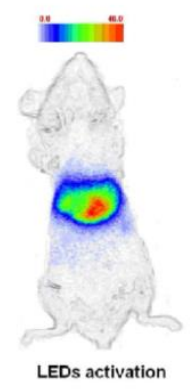

B

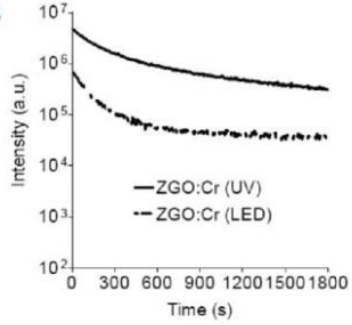

G

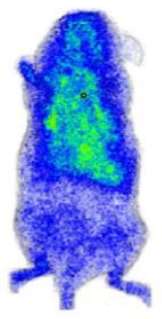

C

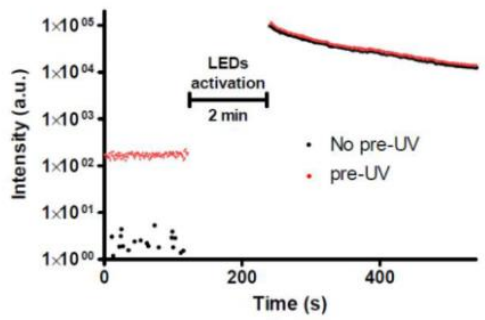

H

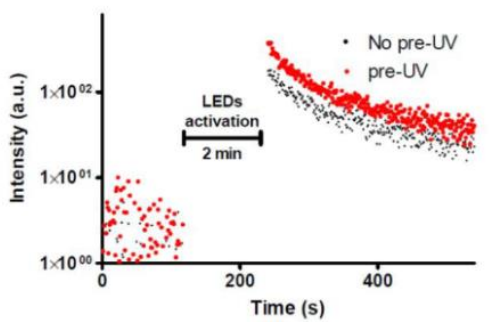

Fig. 5. In vivo imaging with in situ excitable PLNPs. (a-c) Optical properties of ZGO powder after either UV or visible excitation. (d-h) In vivo excitation of unfunctionalized ZGO, (f) PEGylated ZGO in healthy mice, (g) PEGylated ZGO in tumor bearing mice. [28]

This new PLNPs composition opened the way to new researches. ${ }^{121}$ Before ZGO is published (< 2014), very few articles were reported in the literature using PLNPs. However after ZGO is published ( $>$ 2014), the interest of the community for PLNPs applications in biology changed drastically. For 
example, some research groups changed the synthetic procedure in order to get smaller ZGO PLNPs, initial work having been done with $80 \mathrm{~nm}$ nanoparticles. Indeed in 2015 the first synthesis of small ZGO $(<10 \mathrm{~nm})$ was reported. ${ }^{122}$ The authors have used a biphasic approach with toluene and water to control the size of ZGO NPs. The same year, Teston et al. proposed another approach to synthesis ultra-small $\mathrm{ZnGa}_{2} \mathrm{O}_{4}: \mathrm{Cr}^{3+}$ with a diameter close to $6 \mathrm{~nm}$ based on the dissolution of precursors in benzylalcohol followed by microwave irradiation, ${ }^{123}$ offering a reduction of time $(30 \mathrm{~min})$ compared to traditional autoclave conditions ( 24 hours). ${ }^{28}$ This procedure does not require high-temperature heating, allowing the control of the growth of the crystal. The authors showed that these very small particles could be detected in vivo (Fig. 6). Han and co-workers proposed a third strategy to get small water-dispersable ZGO NPs, based on the use of a hydrothermal treatment at $220^{\circ} \mathrm{C}$ with a molar ratio of $\mathrm{Zn} / \mathrm{Ga}$ of $2 /$. $^{124}$
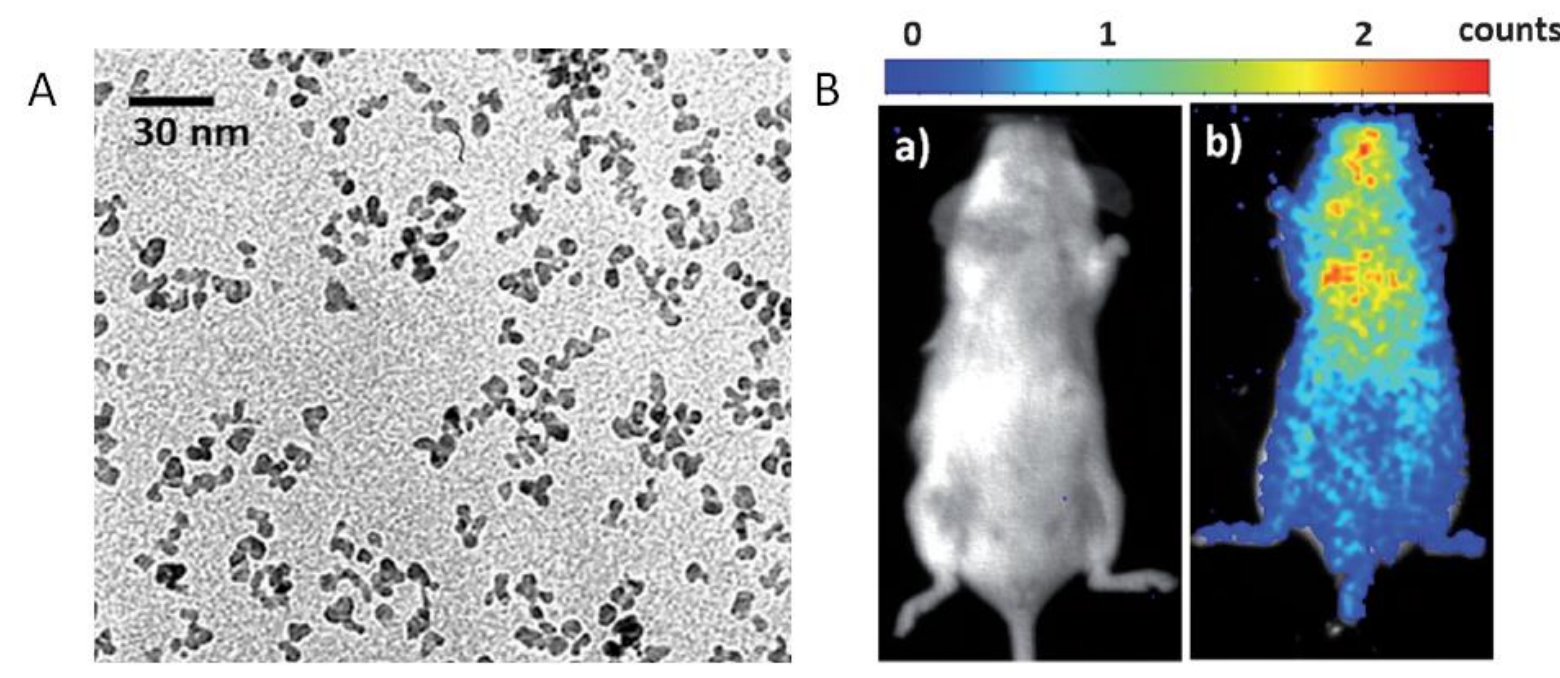

Fig. 6. Ultrasmall PLNPs. (a) Characterisation by TEM. (b) In vivo imaging application [127]

In 2018, Ai et al, from Department of Hepatobiliary Surgery in Zhujiang Hospital (Guangzhou, China), reported the use of small $(\sim 10 \mathrm{~nm}) \mathrm{ZGO}$ nanoparticles in luminescence guided surgery. In their work, the authors used light emitted by ZGO nanoparticles captured in the liver to help surgeron to remove hepatocellular carcinoma (HCC). ${ }^{125}$ Other authors changed the composition of PLNPs or used other physical stimuli such as photostimulation, X-rays, NIR to perform in vivo imaging. This will be highlighted in the following.

\subsubsection{Photostimulation}

In vivo, PLNPs often use thermoluminescence, i.e. the temperature of the animal body to release the trapped charges in order to lead to light emission. In 2013, a group synthesized PLNPs able to be detrapped by using low energy light. This process called photostimulating persistent luminescence (PSPL, Fig. 3, step 2) is another possible physical stimulus. For that purpose, $\mathrm{LiGa}_{5} \mathrm{O}_{8}: \mathrm{Cr}^{3+}$ was prepared and used for cell labelling and tracking in vivo. ${ }^{29,126}$ To favor their internalization into cells, $\mathrm{LiGa}_{5} \mathrm{O}_{8}: \mathrm{Cr}^{3+}$ nanoparticles were coated with polyethylene imine (PEI), a cationic polymer, ${ }^{127,128}$ and labelled cells were excited ex vivo with UV light and injected into mice. Their localization in vivo was followed over the time without (Fig. 7, top) or with photostimulation (Fig. 7, bottom). 

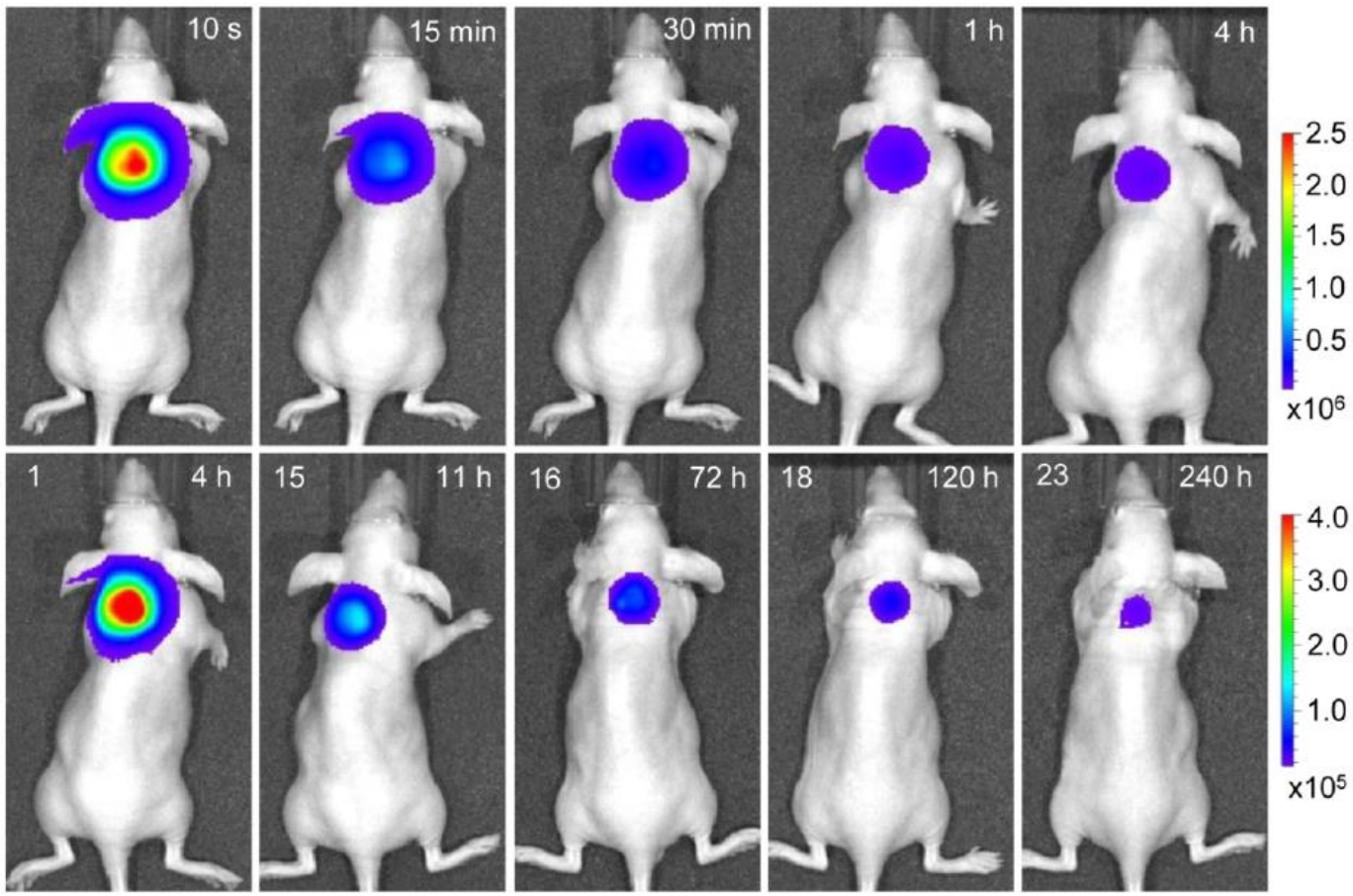

Fig. 7. In vivo imaging using photostimulated $\mathrm{LiGa}_{5} \mathrm{O}_{8}: \mathrm{Cr}$ PLNPs in order to track labeled cells in vivo at different time after injection [131].

\subsubsection{X-rays excitation}

As discussed in section 2, a limit of visible light to excite NPs is its low penetration into tissues. So it is very important to develop probes and excitation sources able to exceed this limit. Among the different possible excitation sources, we can mention X-rays. ${ }^{129} \mathrm{X}$-rays are one possible physical stimulus able to excite luminescent centers and also host matrix (Fig. 2 and Fig. 8A) in order to produce light. Compared to classical methods of excitation (UV/visible/NIR), X-rays have the advantages of weaker diffusion and higher penetration in tissues. Moreover easier reconstruction occurs for tomography, ${ }^{130}$ and more precise localization of the probe in the animal happens (Fig. 8B). As a proof of concept, Xue et al. used $\mathrm{ZnGa}_{2} \mathrm{O}_{4}: \mathrm{Cr}^{3+} \mathrm{NPs}$ and evaluated the efficacy of low excitation $\mathrm{X}$-rays source to excite $\mathrm{ZGO}$ in vivo (Fig. 8). ${ }^{30}$ 

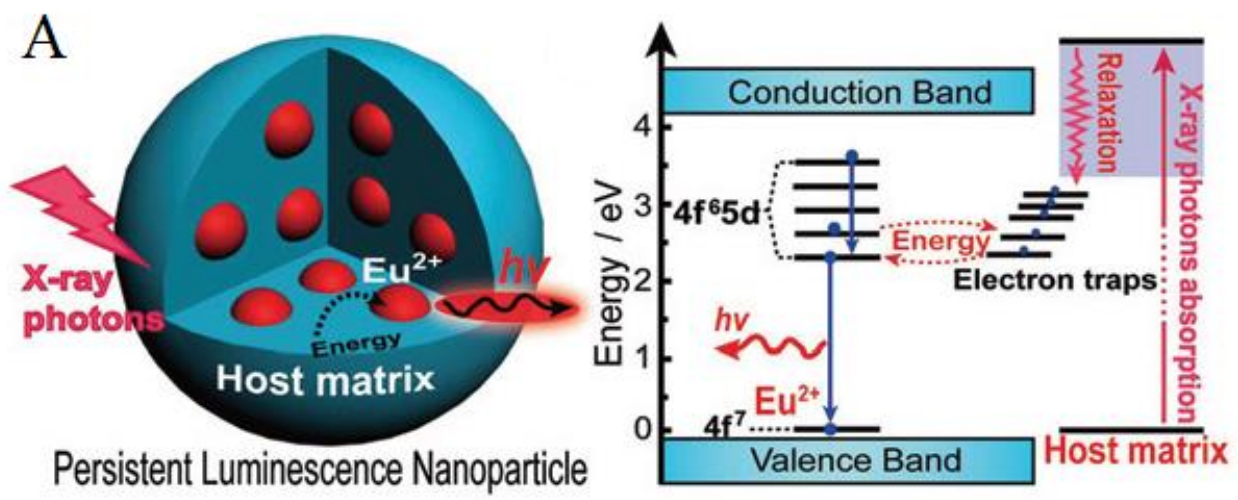

$\mathrm{B}$

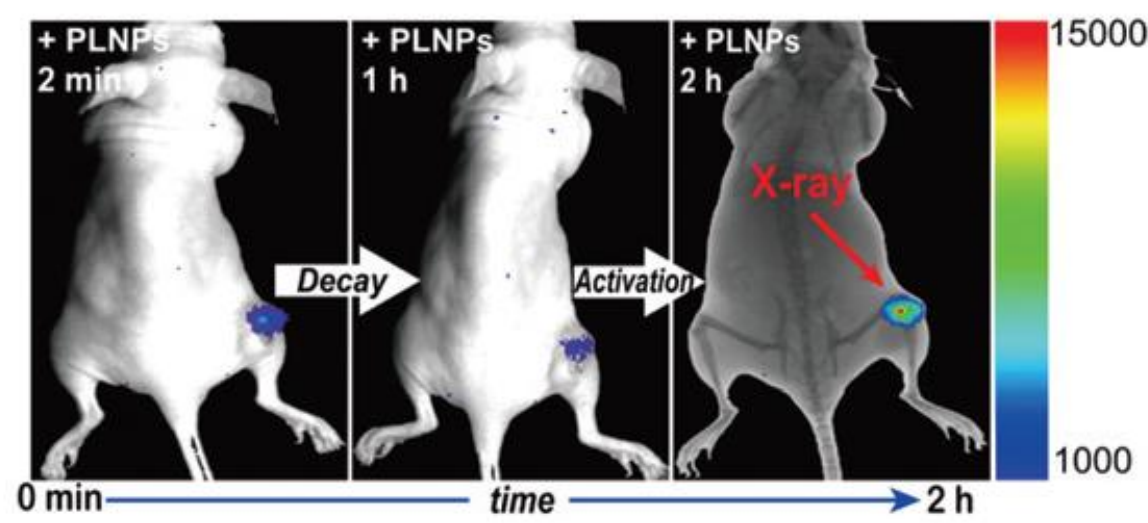

Fig. 8. (a) Principle of in vivo imaging using X-rays excitation. (b) Application in vivo. [30]

\subsubsection{NIR excitation}

Another strategy to effectively excite the probe in vivo, as presented in physical section 2 (Fig. 3) is to get PLNPs with both excitation and emission bands localized in the biological window. Hao and coworkers recently used this strategy in order to propose another stimulation strategy using upconversion PLNPs (named UC-PLNPs) by using $\mathrm{Zn}_{3} \mathrm{Ga}_{2} \mathrm{GeO}_{8}: \mathrm{Cr}^{3+}, \mathrm{Yb}^{3+}, \mathrm{Er}^{3+} \mathrm{NPs}$. The presence of $\mathrm{Yb}^{3+}$ into the nanomaterial allows doing excitation at $980 \mathrm{~nm}$. This wavelength excite $\mathrm{Yb}^{3+}$ which then transferred its energy to $\mathrm{Er}^{3+}$ and which is finally stored into the traps. ${ }^{131}$ In 2018, Chang and co-workers used the same idea with another matrix, made of $\mathrm{Zn}_{2} \mathrm{SiO}_{4}: \mathrm{Mn}$ doped with $\mathrm{Y}^{3+}, \mathrm{Yb}^{3+}, \mathrm{Tm}^{3+}$. Here again $\mathrm{Yb}^{3+}$ can be excited by a laser at $980 \mathrm{~nm}$ and can transfer its energy to $\mathrm{Tm}^{3+}$ before being stored into electron traps. The authors have used such UC-PLNPs to label macrophages ex vivo in order to target and image tumor in vivo. ${ }^{132}$ This strategy can be of particular interest in cell-based therapy applications.

\subsection{Multimodal imaging nanoprobes}

Multimodal imaging is a relatively new strategy used in bioimaging in order to provide more accurate information. ${ }^{133,134}$ Insofar as each imaging modality has advantages and disadvantages in terms of sensitivity, resolution, ${ }^{135}$ the concept of multimodal imaging is to combine into the same imaging tool 
different modalities that are complementary, for example optical imaging with MRI in order to benefit from each. For that purpose, different alternatives have been reported.

\subsubsection{Gd containing PLNPs}

Gadolinium is an MRI contrast agent largely used in clinic. Several strategies have been reported using this cation to have access to bimodal imaging PLNPs (Fig. 9). In 2014, Yan et al. introduced DTPA/Gd complexes on the surface of $\mathrm{Zn}_{1.1} \mathrm{Ga}_{1.8} \mathrm{Ge}_{0.1} \mathrm{O}_{4}$ NPs in order to get a bimodal imaging agent, that could be detected by optical imaging (thanks to the PLNPs) and by MRI (thanks to $\mathrm{Gd}^{3+}$ ) (Fig. 9A, left). ${ }^{136}$

In 2015, other authors reported another strategy to also have a bimodal imaging agent. In that case, the authors incorporated various amount of $\mathrm{Gd}^{3+}$ ions at the beginning of the synthesis, in order to substitute some $\mathrm{Ga}^{3+}$ ions of the matrix by $\mathrm{Gd}^{3+}$ ions (Fig. 9A, middle). ${ }^{35}$ In such conditions, contrary to the previous strategy, the surface of the NPs remains accessible for further functionalization. The authors have shown that such nanoprobe could be easily detected by optical imaging (Fig. 9C) and by MRI giving a negative contrast into the liver (Fig. 9B, D-E).

In 2017, a third strategy was proposed based on the use of ZGO doped with $\mathrm{Cr}^{3+}$ and $\mathrm{Sn}^{4+}$ incorporated into silica (ZGOCS@MSNs) and the all wrapped by a shell of $\mathrm{Gd}_{2} \mathrm{O}_{3}$ (Fig. 9A, right) ${ }^{39}$. In that case, contrary to the previous strategy, a positive contrast was obtained after capture by the liver.

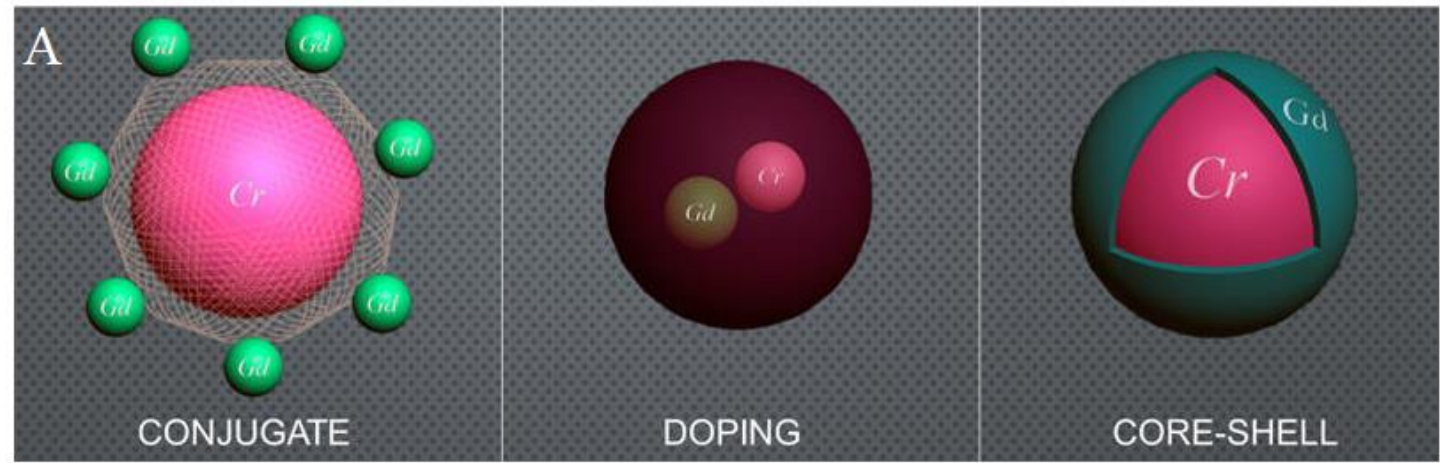

B

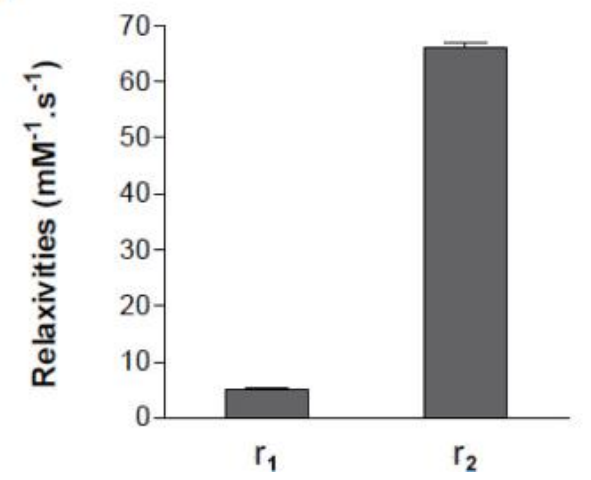

$\mathrm{C}$

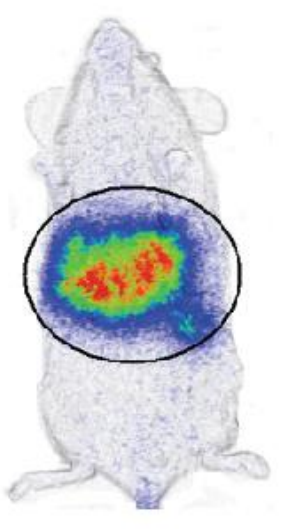

$\mathrm{D}$

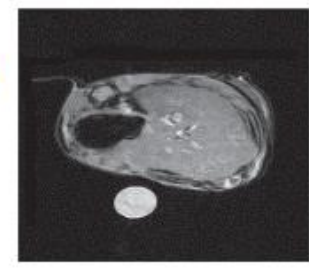

$\mathrm{E}$

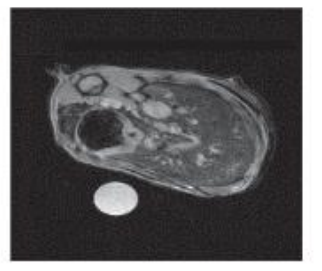

Fig. 9. (a) Strategies to prepare $\mathrm{Gd}^{3+}$ containing PLNPs. (b-e) Examples of in vivo bimodal imaging applications.

$[35,39,142]$ 


\subsubsection{Iron oxide/PLNPs nanohybrids}

In addition to gadolinium, ultrasmall iron oxide nanoparticles (USPIO) are also used in clinic as negative $\left(\mathrm{T}_{2}\right)$ MRI contrast agents. In 2015, Teston et al synthesized the first mesoporous nanohybrids (MPNHs) made of PLNPs and USPIOs incorporated into mesoporous silica to get a bimodal imaging agent (Fig. 10). ${ }^{37}$ In addition to its efficiency as a bimodal imaging probe (Fig. 10B), the authors observed that these nanohybrids could be attracted by a magnet (Fig. 10C). They have later used this property to label cells and have demonstrated that such labeled cells could be attracted in vivo using a magnet (Fig. 10D-E) ${ }^{38}$ This result opens alternative approaches in cells based therapy trials.

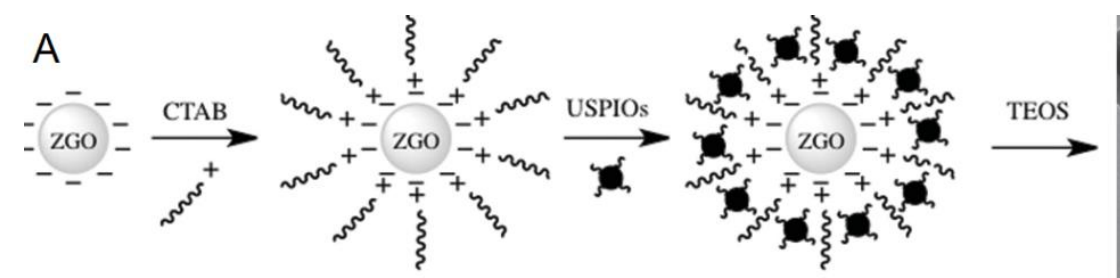

B

C
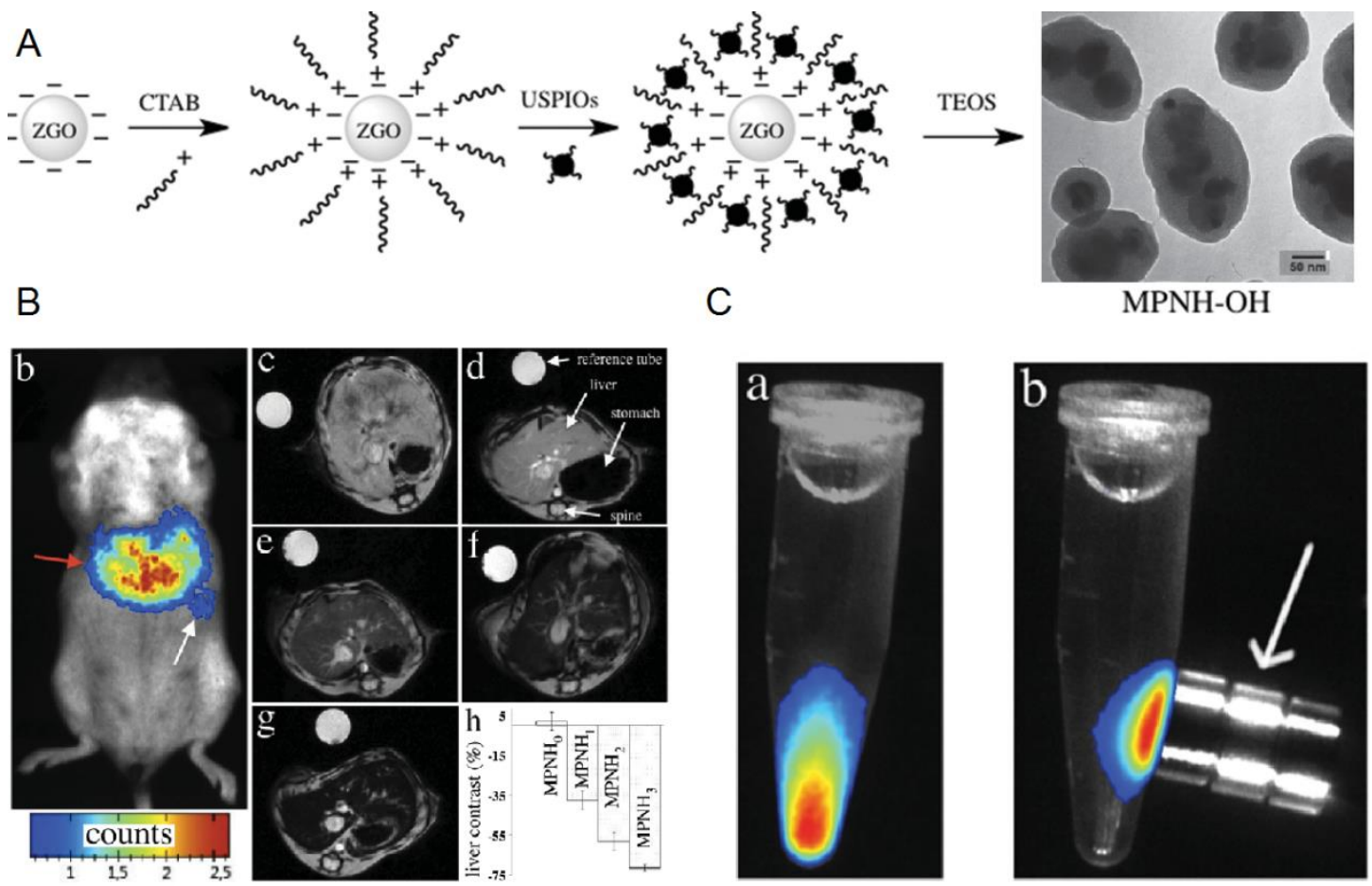

D

$E^{-75}$
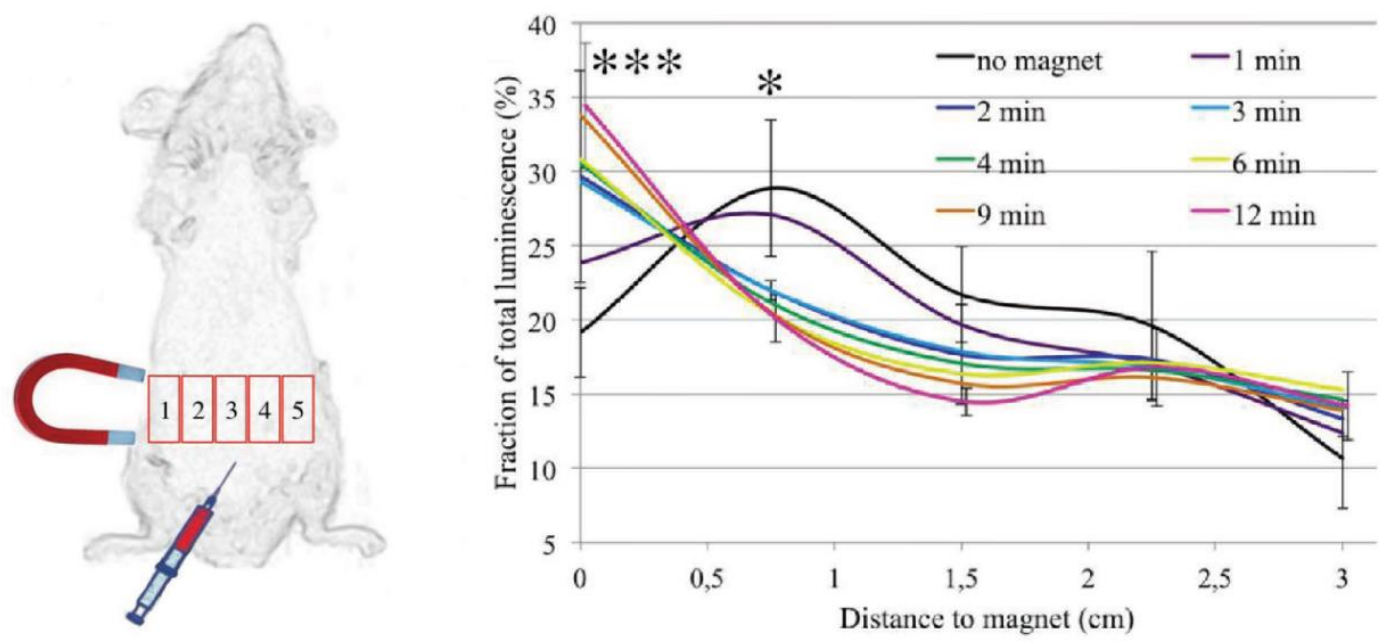

Fig. 10. Nanohybrids (MPNHs) made from iron oxide NPs and PLNPs. (a-c) Synthesis and characteristics. (d-e) Cell labelling and in vivo magnetic targeting. [37, 38] 
This section has highlighted some of the main applications of PLNPs, reported since 2007, using different physical stimuli (UV, visible, NIR, X-rays) in bioimaging. More recently such NPs have also shown interest in therapy. This approach will be presented in the following section.

\section{Nanotheranostics}

With the development of nanomedicine, the conception of nanoparticles able to be used not only for imaging as presented in section 3, but also as a therapeutic agent has emerged, by incorporating into the same nanosystem both imaging and therapeutic property. Such hybrids are called nanotheranostics. ${ }^{137}$ To be used in vivo, such nanomaterials should have several advantages: ${ }^{138}$ (i) preferential accumulation of the nanotheranostics in the organ to be imaged/treated, (ii) ability to deliver the therapeutic agent at the action site, and (iii) the nanotheranostics must be as safe as possible. This approach is actually under investigation for the treatment of several diseases. ${ }^{139,140,141,142}$ In this section, we will highlight the emerging applications of persistent luminescence for the development of new nanotheranostics using as before different physical stimuli (X-rays, LED, NIR) to detect and follow the distribution and efficacy of therapeutic agents.

\subsection{DOX loaded nanotheranostics}

Because of its biocompatibility, mesoporous silica $\left(\mathrm{mSiO}_{2}\right)$ which consists of silica nanoparticles containing a large number of pores in its structure is often used as a carrier in order to deliver drugs. ${ }^{143}$ But a limit of this approach is the inability to monitor the biodistribution of mesoporous silica because it is undetectable by any imaging method. In 2014, Maldiney et al. proposed a solution based on the use of persistent luminescence as a powerful property to follow in vivo the biodistribution of $\mathrm{mSiO}_{2}$ loaded with doxorubicin (DOX). ${ }^{144}$ In vitro, the authors have shown that such nanotheranostics can be used on cancer cells in order to induce a cytotoxic effect, contrary to the non-loaded system. In vivo, the presence of DOX has a little effect on the luminescence of the nanoprobes. ${ }^{108}$

In 2016, Zhang and co-workers developed a variant of the previous system in which mesoporous silica can be made not only with PLNPs (ZGO) as before but also with an MRI contrast agent $\left(\mathrm{Gd}_{2} \mathrm{O}_{3}\right)$ (Fig. 11). ${ }^{145}$ This nanotheranostic was loaded with DOX in order to monitor its biodistribution in healthy and in tumor bearing mice (Fig. 11, bottom left). 


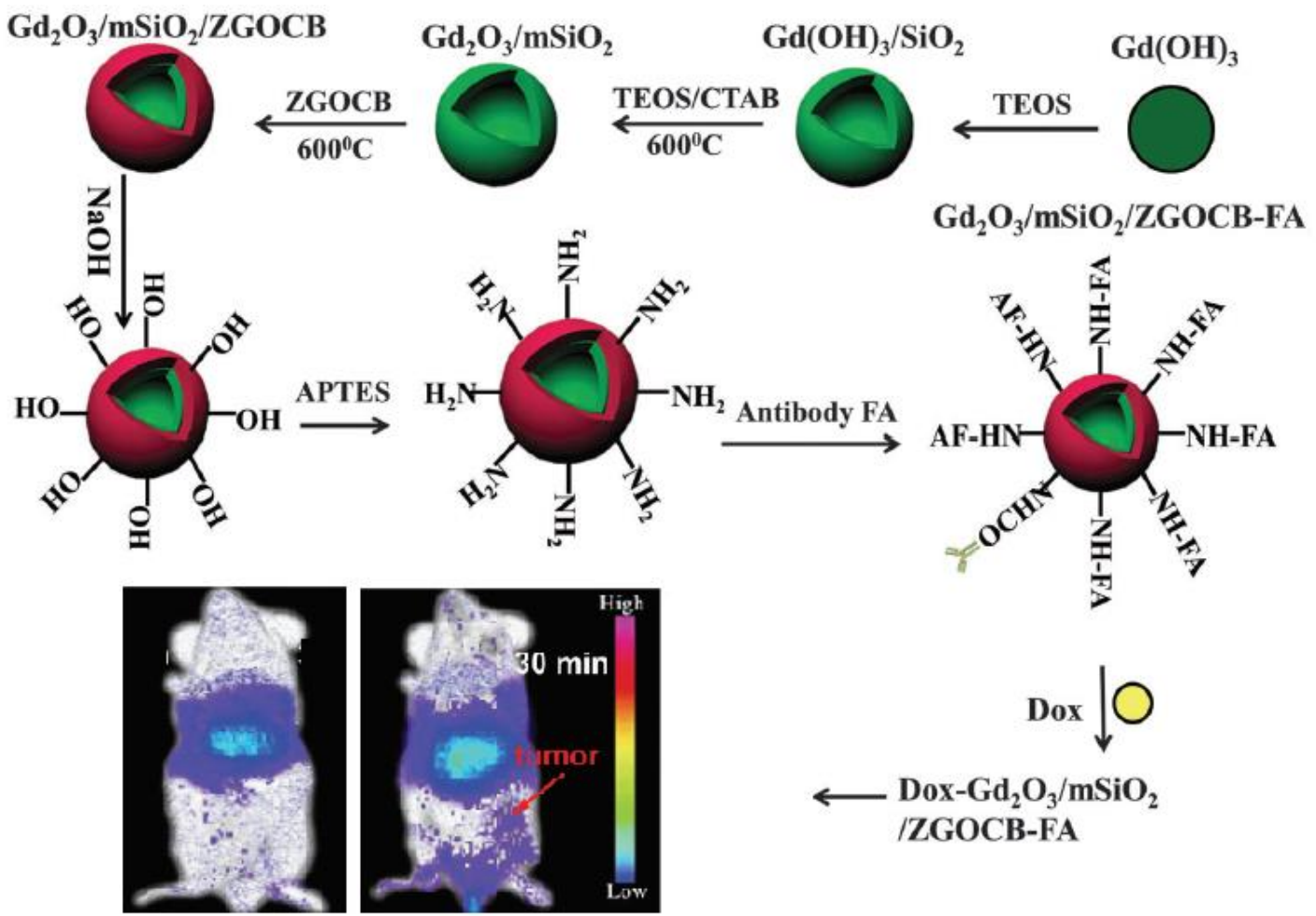

Fig. 11. Synthesis of mesoporous $\mathrm{Gd}_{2} \mathrm{O}_{3} / \mathrm{ZGO}$ nanostructure, loading with DOX and example of in vivo application. [155]

\subsection{Photodynamic therapy with PLNPs}

Photodynamic therapy (PDT) is a technique used for the treatment of certain cancers, such as skin cancers. ${ }^{146}$ It is based on the use of a photosensitizer (PS), which most of the time is a polyaromatic organometallic complex such as porphyrins, phthalocyanines, able to be excited by light. Among the different PS, Porfimer has been approved by the United States Food and Drug Administration (FDA) ${ }^{147}$ In the dark such molecules are not toxic, but upon excitation, the photosensitizer absorbs light and transfer part of this energy to surrounding oxygen molecules generating reactive oxygen species (ROS) such as ${ }^{1} \mathrm{O}_{2}$ or $\mathrm{O}_{2}^{-}$. When produced into cells, these highly instable species react rapidly with surrounding molecules such as unsaturated lipids or DNA resulting in cell death. ${ }^{148149}$ However a limit of this technique is the difficulty to excite the PS in deep tissues. ${ }^{150}$ Several strategies have been proposed to solve this problem, such as the use of endoscopic technologies allowing illuminating internal cavities, such as bladder, prostate, and esophagus. ${ }^{151}$ Other strategies are based on the use of high-dose of X-rays. ${ }^{152}$ But such irradiations can cause damage to healthy tissues. ${ }^{153}$

As discussed in section 2 and 3, persistent luminescence is an innovative phenomenon in which the excitation energy can be stored and then used over very long period of time. PLNPs alone have limited impact on cancer cells. ${ }^{154}$ The following paragraph will show how it is possible to use PLNPs in PDT.

\subsubsection{X-rays excitable nanotheranostics}

In 2015, Xie and co-workers have designed a nanosystem composed of PLNPs made of $\mathrm{SrAl}_{2} \mathrm{O}_{4}: \mathrm{Eu}^{2+}$ (SAO) and a photosensitizer (MW540) incorporated into mesoporous silica. ${ }^{155}$ The authors have 
shown that such a nanosystem is able to absorb X-ray photons in order to excite SAO NPs and the visible photons emitted by the PLNPs are able to activate photosensitizers (MW540) present into the nanosystem in order to produce ROS. In this work, the authors have shown that such nanosystem can efficiency reduce the tumor growth, compared to X-rays treatment alone or PLNPs alone (Fig. 12).
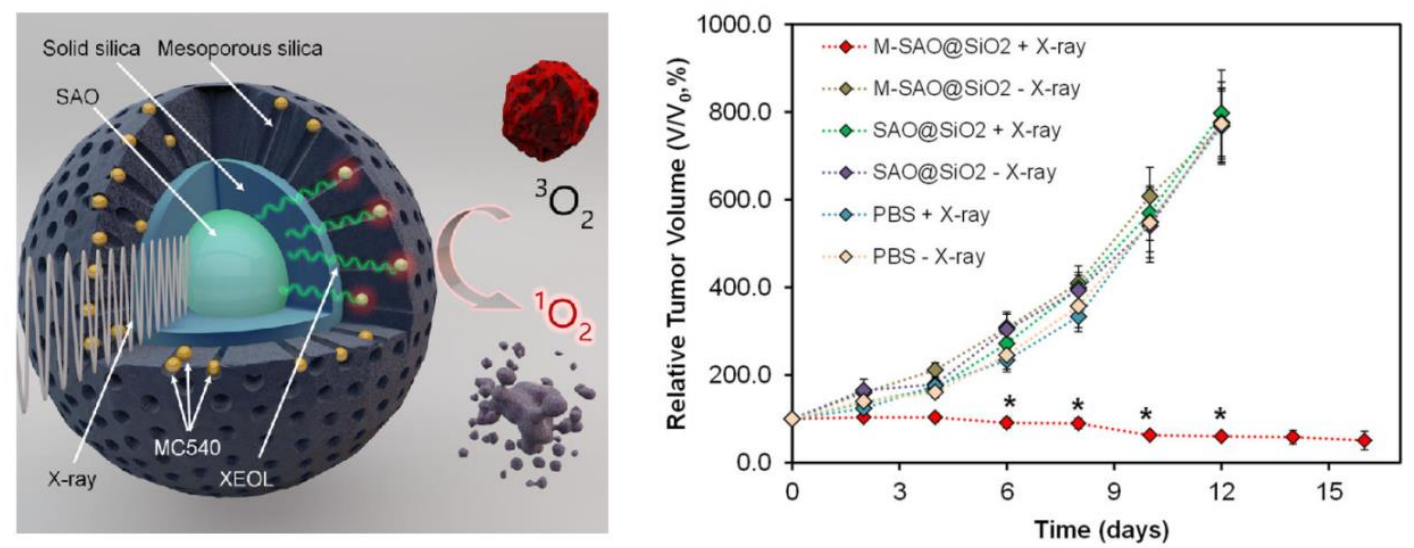

Fig. 12. Nanosystem made of PLNPs (SAO) and a PS agent (MC540) incorporated into mesoporous silica. [165]

In 2018, Yang and co-workers have used another strategy to develop X-ray excitable PDT/PLNPs. They have shown that another photosensitizer (PS) such as Zn (II) phthalocyanine tetrasulfonic acid (ZnPcS4) can be covalently linked to ZGO PLNPs to fabricate PDT nanosystem (ZGO:Cr/ZnPcS4). When the X-ray irradiation is stopped, the persistent luminescence light emitted by ZGO is able to excite in continuously the PS allowing reducing the dose of X-ray and in plus minimizing the side effects of X-ray treatments. ${ }^{156}$

\subsubsection{LED excitable nanotheranostics}

In 2018, Zhang and co-workers developed another strategy for tumor imaging and photodynamic therapy based on the use of LED as an alternative physical stimulus. ${ }^{157}$ To be able to load therapeutic molecules, they used carbon spheres as a template to absorb the different cations precursors of luminescence on the surface of carbon spheres. After calcination at about $800^{\circ} \mathrm{C}$ the carbon spheres are degraded allowing forming porous PLNPs. This porous material was used to load a PS made of silicon porphyrin (Si-Pc). Excitation at $650 \mathrm{~nm}$ allows the transfer of the persistent luminescent signal to Si-Pc. Such phenomenon was used in vivo and its efficacy was evaluated on tumor bearing mice and compared to non-treated mice. ${ }^{167}$

\subsubsection{NIR excitable nanotheranostics}

Zhang et al. used another strategy based on UC-PLNPs loaded with photosensitizers to generate ROS. For that purpose, the authors prepared a nanohybrid made of UC-PLNPs composed of $\mathrm{NaYF}_{4}$ doped with $25 \%$ of $\mathrm{Yb}^{3+}$, and $0.5 \%$ of $\mathrm{Tm}^{3+}$, a persistent luminescence material made of $\mathrm{SrAl}_{2} \mathrm{O}_{4}: \mathrm{Eu}^{2+}, \mathrm{Dy}^{3+}(\mathrm{SAO})$, and a photosensitizer made of rose Bengal, the whole incorporated into a biocompatible polymer made of polydimethylsiloxane (PDMS). ${ }^{158}$ In such system, NIR light (980 nm laser) can be used as a physical stimulus to excite UC-PLNPs (Fig. 13 A). The blue light emitted by 
UC-PLNPs is used to excite SAO which in turn emits green light able to excite the PS (rose Bengal). The main advantage of this process is that ROS can be produced for about $30 \mathrm{~min}$ without constant irradiation (Fig. 13). Thanks to the good tissue penetration of NIR laser, generation of singlet oxygen in deep tissue $(\sim 4 \mathrm{~mm})$ is possible. The efficacy of such nanohybrid for the inhibition of tumor proliferation was evaluated on subcutaneous $4 \mathrm{~T} 1$ tumor bearing mice (Fig. 13B).

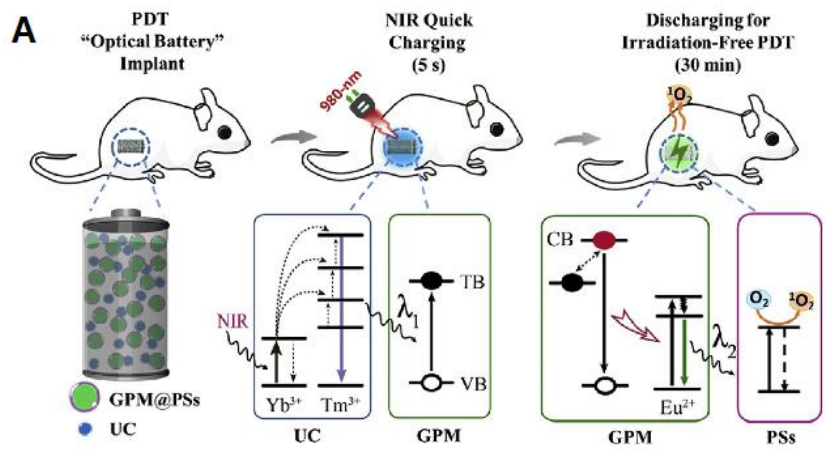

B

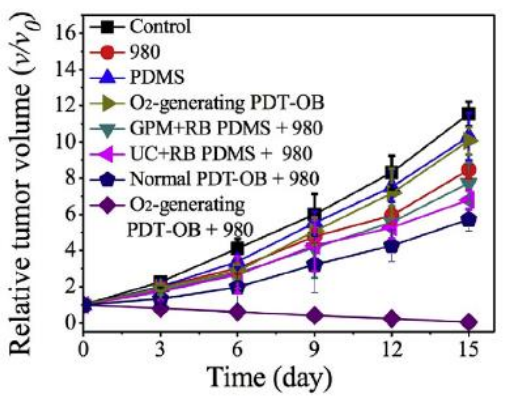

Fig. 13. Optical battery made of GPM, UC and PS activated by NIR light. [168]

\subsection{Photothermal therapy}

Another strategy developed in recent years for the treatment of cancers is the conversion of light radiations to generate heat to destroy cancer cells. This technique is called PTT for photothermal therapy. ${ }^{159}$ For that purpose, a molecule able to convert light excitation into heat (ideally beyond $42^{\circ} \mathrm{C}$ ) in order to kill cancer cells is used. Among the FDA-approved molecules for PTT, indocyanine green (ICG) is often used in hyperthermia since it can absorbs near-infrared light to produce heat where it is present. ${ }^{160}$ To improve the local delivery of ICG in order to enhance its efficacy in vivo, different nanosystems are under development. ${ }^{161,162}$ Among the emerging strategy, the use of persistent luminescence to extend the in vivo production of heat is considered.

\subsubsection{PTT induced by LED excitation}

In 2017, Chang and co-workers developed a nanosystem based on ZGO NPs and ICG incorporated into mesoporous silica (Fig. 14A). ${ }^{163}$ In such system, ZGO is both used to visualize the nanosystem in vivo after injection and also to excite ICG. Indeed the persistent luminescence signal emitted between 680 to $730 \mathrm{~nm}$ by ZGO after excitation can be absorb by ICG which in return will produce heat at the site of action (Fig. 14B). Using such nanosystem, the authors have shown that after irradiation, they were able to increase the local temperature in order to kill cancer cells. The authors have shown that such nanosystem is much more efficient than when using the irradiation source alone or with ICG (Fig. 14C). 

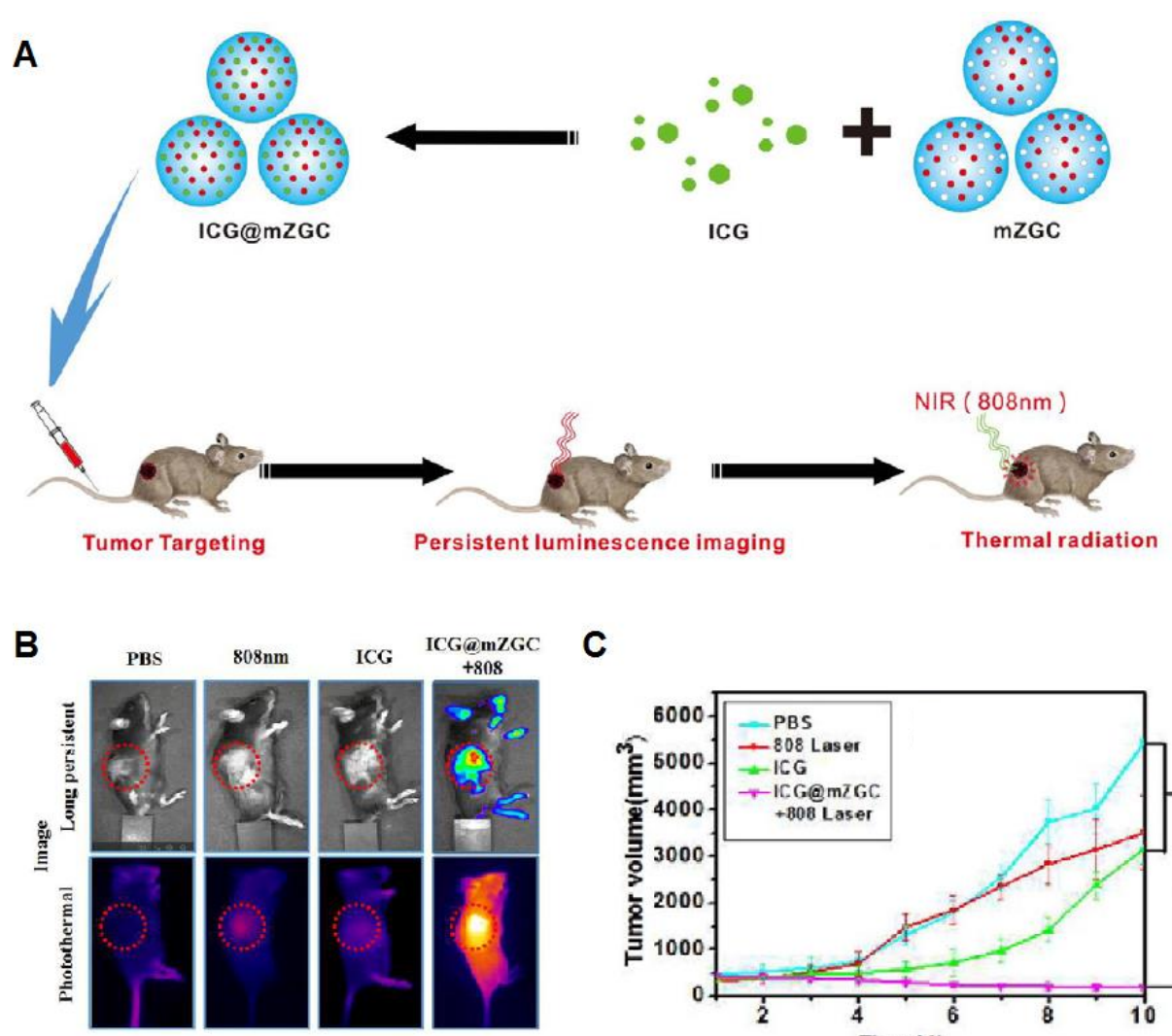

C

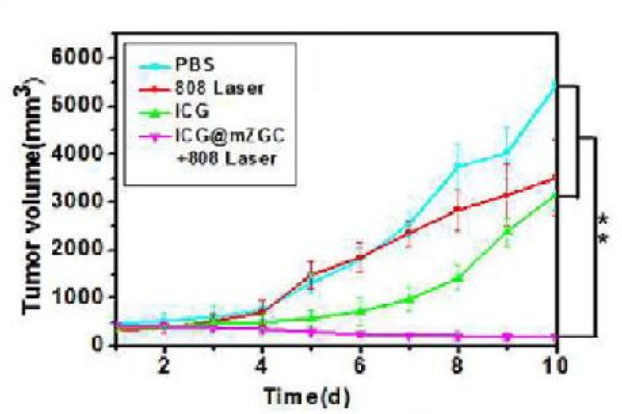

Fig. 14. PTT induced by using ICG loaded in PLNPs. [173]

\subsubsection{PTT induced by NIR excitation}

Finally, Cao and co-workers developed an alternative strategy to favor heat production in deeper tissues based on the use of upconverting PLNPs. ${ }^{61}$ For this purpose, the UC-PLNPs were doped with $\mathrm{Er}^{3+}$ and $\mathrm{Tm}^{3+}$ in order to allow excitation at $980 \mathrm{~nm}$. The photons emitted by UC-PLNPs at about 650 $\mathrm{nm}$ can be then absorbed by ICG to produce heat. Using thus nanosystem, the authors have shown that the local temperature measured by an external thermal camera can be increased (Fig. 15, bottom), and this was successfully used to control the tumor growth in vivo. 

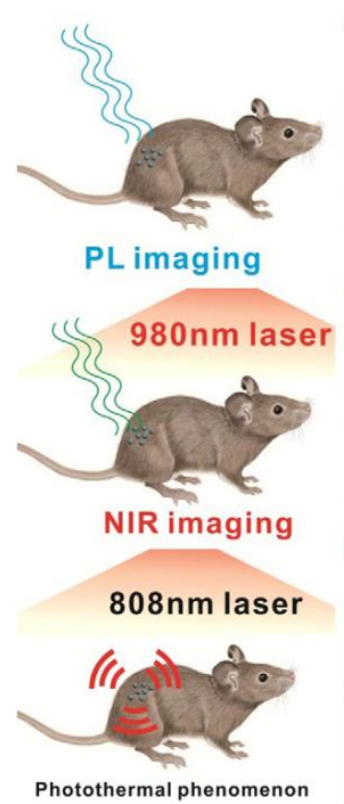
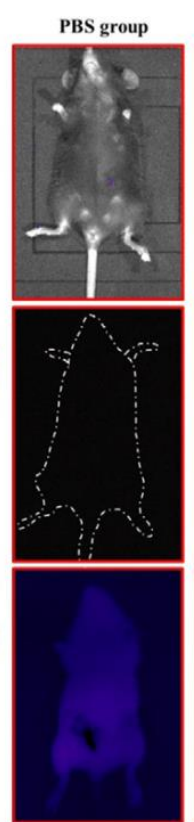
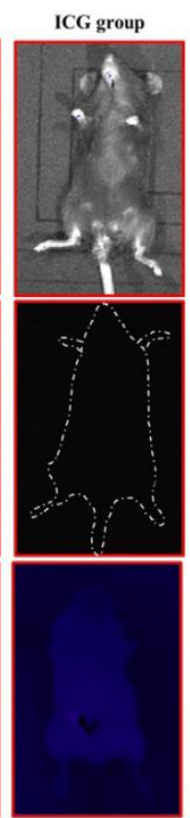
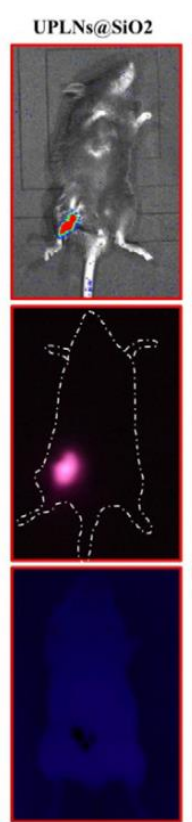
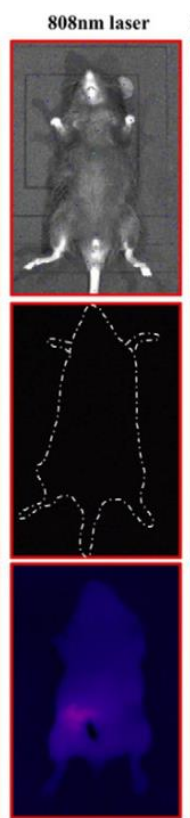

(UPLNs+ICG)@SiO2

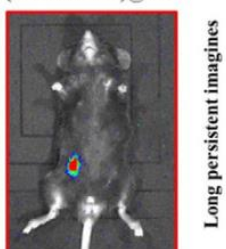

Fig. 15. PTT induced by NIR excitable PLNPs. [61]

\section{Biocompatibility of PLNPs}

To be used in vivo, all these potent nanosystems should be highly biocompatible. In general, good biocompatibility is obtained when a nanomaterial interacts with the body without inducing toxicity. ${ }^{164}$ Once injected into the blood stream, the physico-chemical properties of nanoparticles, known as their "synthetic identity" will change a lot, mainly due to interactions with biomolecules such as lipids, sugars and proteins. ${ }^{165}$ This forms a corona around the surface of nanoparticles, known as the "biological identity" ${ }^{176}$ Such identity is what the biological system sees, and it also determines the distribution, metabolism, excretion, and toxicity of the nanomaterials. Different parameters such as the nanoparticle size and the coating greatly affect the biodistribution. ${ }^{166}$ Nanoparticle with size $<6 \mathrm{~nm}$ (hydrodynamic diameter) are able to pass through the pores of the glomerulus in the kidneys and cleared by renal filtration. On the contrary, nanoparticles $>6 \mathrm{~nm}$ (hydrodynamic diameter) will stay in the body and be sequestered by the reticulo-endothelial system (RES) and macrophages present in the liver, spleen and lungs. ${ }^{167}$ In liver, nanoparticles can be captured either in Kupffer cells, which are liver resident macrophages or in hepatocytes. In the last case the nanoparticles will be cleared by the hepatobiliary system. This could be realized in hours to weeks. ${ }^{168}$ On the contrary, if the nanoparticles are captured in Kupffer cells, they could stay for months to years. ${ }^{169}$ In order to reduce the adsorption of serum proteins on the nanoparticles to avoid captured of nanoparticles by hepatic tissue, efforts are employed to delay or reduce their phagocytosis. Different strategies to coat the surface of NPs by molecules or polymers have been developed. ${ }^{170171}$ Many studies have demonstrated that the PEGfunctionalized NPs adsorb fewer proteins and are less ingested by cells. ${ }^{172}$ Precoating NPs with proteins or the formation of a protein corona on their surface could shield NPs from binding with membrane proteins and therefore reduce cellular uptake of NPs. ${ }^{173}$ Thereby, biocompatibility is an important prerequisite for nanoparticles being used in vivo.

The main matrixes presented above are either zinc gallium oxide ZGO NPs, or derivatives, incorporated into mesoporous silica. The toxicity of mesoporous silica is well known since this material is used since more than a decade. 
The biocompatibility of mesoporous silica has been highly investigated. ${ }^{174,175}$ For example it has been shown that no abnormality could be observed in various tissues such as heart, liver, spleen, lung and kidney after intravenous injection into mice. This suggests that the mesoporous silica has not significant tissue toxicity. The same conclusion was obtained by Zink and Tamanoi after intraperitoneal injection. ${ }^{176}$ Even after high dose injection $\left(50 \mathrm{mg} \cdot \mathrm{kg}^{-1} /\right.$ day $)$, the acute toxicity of this material was negligible. It's only at very high dose $\left(>1000 \mathrm{mg} \cdot \mathrm{kg}^{-1}\right)$ that this material was toxic either after intravenous or intraperitoneal injection. ${ }^{177}$

Concerning persistent luminescence nanoparticles by themselves, one article has been published by Ramirez-Garcia et al. concerning the biocompatibility and toxicity of ZGO in vivo. Indeed, this information is of great importance for future applications of such nanomaterials. In their study, mice were injected once with increasing amounts of ZGO (from 1 and $8 \mathrm{mg}$ of ZGO per mice). The effect was analyzed in the short term ( 24 hours), middle term (30 days) and longer term ( 6 months) after injection. As could be seen in Fig. 16, only elevated amount of ZGO ( $8 \mathrm{mg} / \mathrm{mouse})$, which is about 5 times higher than the amount classically used for in vivo imaging, causes a significant variation of weight of animals.
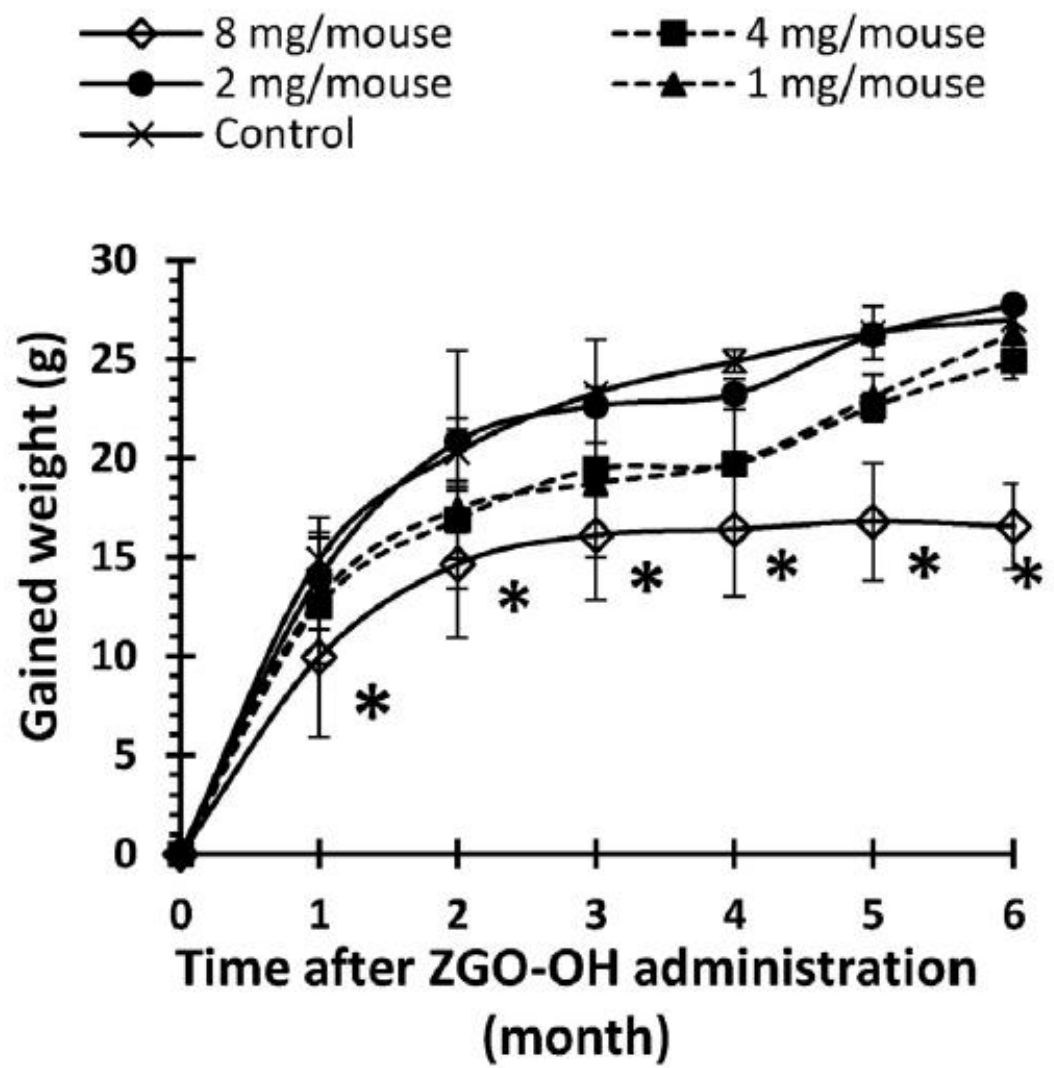

Fig. 16. Influence of injected dose of ZGO-OH on mice body weight over a 6 months period [32].

In addition to that, a set of factors were measured such as oxidative stress, and the hematic biometry. ${ }^{32}$ The authors observed that only high concentrations of nanoparticles with hydroxyl groups on their surface (ZGO-OH) generate oxidative stress in liver, as well as increase the number of white blood cells 24h after injection. No toxicological effects were observed with PEGylated ZGO showing the protective effect of such hydrophilic polymer. It would be also interesting to evaluate the genotoxic 
effect of PLNPs. More investigations are also required to evaluate the biotransformation of such nanoprobes over the time.

\section{Conclusions and perspectives}

In a decade, persistent luminescence has emerged as a useful property for the design of new optical imaging nanoprobes. Thanks to the long lasting luminescence, from few minutes to several hours after the end of excitation, imaging in the first transparency window (BW-I) with high sensitivity was reported by several research groups. Nowdays, more than 40 research groups all over the world use this strategy to develop optical nanoprobes and more than 200 papers have been published.

Beyond to their uses for imaging, and more recently for therapy, new applications based on this technology are emerging. The first one concerns their interest for the development of sensitive in vitro biosensors for the detection of small amount of analytes. ${ }^{178,179}$ As a second example, we can cite the emerging use of persistent luminescence for the development of nanothermometers, for which the idea is to link the luminescence (intensity, decay profile) emitted by the nanoprobes to temperature variations in vivo at the nanoscale (thermoluminescence). The decay profiles in persistent phosphors strongly depend on the temperature as the traps released are temperature dependent. In that case, the time scale can be in the order of the seconds rather than microseconds/milliseconds for the usual lifetime decays measurements. This allows the emission to be recorded with quite simple optical devices. Indeed temperature measurement is an important parameter to control in hyperthermia (as presented in section 4), since this precision nanomedicine method used to kill malignant cells by thermal ablation has received European regulatory approval for tumours' treatment. ${ }^{180,181,182,183,184}$ Actually the temperature is only measured on the surface of the body using a NIR-camera, which doesn't allow to access the in situ local temperature.

Future works on persistent luminescence concern the development of new probes compositions and also new detectors able to be used in the second biological window (NIR -II, > $1000 \mathrm{~nm}$ ). Indeed, optical imaging in this biological window (BW-II, BW-III, from 1.0 to $1.7 \mu \mathrm{m}$ ) has showed significant attention. Indeed a limit of imaging in BW-I is the scattering of light. On the contrary, beyond 1000 $\mathrm{nm}$, photons can provide high spatial resolution, deeper tissue penetration and reduced scattering. ${ }^{185,186,187}$ Furthermore, imaging in this region addresses several challenges: minimal autofluorescence of biological tissue leading to increased sensitivity. ${ }^{188}$ In such conditions, a whole mouse can be rendered translucent. ${ }^{189,190}$ But for that purpose, probes with new compositions must be developed. Recently, Qiu and co-workers reported a strategy for moving the emission of persistent phosphors at around 1270 to $1430 \mathrm{~nm}$ by synthetizing $\mathrm{Ni}^{2+}$ doped $\mathrm{Zn}_{1+\mathrm{y}} \mathrm{Sn}_{\mathrm{y}} \mathrm{Ga}_{2-\mathrm{x}-2 \mathrm{y}} \mathrm{O}_{4}{ }^{191}$ In the same idea, Ueda, ${ }^{192}$ Tanabe $^{193}$ and our groups recently reported new compositions able to be used in the second transparency window. ${ }^{194}$ Biological applications of persistent luminescence are probably just beginning. Other applications of luminescent materials have also been reported in other area, such as in light emitting diodes (LEDs). ${ }^{195196}$ 


\section{Acknowledgments}

This work was supported by grants from the French national research agency (ANR Natlurim and ANR PEPSI 14-CE08-0016-01), by Idex Sorbonne Paris-Cité, by CNRS, by Biospace Lab, by the PRC Japon JSPS/French Bilateral grant (PRC1248) and by PHC Procore (33122PA). The authors also acknowledge all their collaborators: Q. le Masne de Chermont, T. Maldiney, E. Teston, G. RamirezGarcia, D. Gourier, A. Bessière, C. Chanéac, M. Pellerin, F. Gazeau and L. Laumonier. 


\section{References}

${ }^{1}$ E. M. C. Hillman, C. B. Amoozegar, T. Wang, A. F. H. McCaslin, M. B. Bouchard, J. Mansfield and R. M. Levenson, Philos. Trans. R. Soc., A, 2011, 369, 4620-4643.

${ }^{2}$ M. De Jong, J Essers, W.M. van Weerden, Imaging preclinical tumour models: improving translational power. Nat. Rev. Cancer 2014, 14, 481-493.

${ }^{3}$ H. S. Choi, W. Liu, F. Liu, K. Nasr, P. Misra, M. G. Bawendi, J. V. Frangioni, Design considerations for tumour-targeted nanoparticles, Nature Nanotechnology 2010, 5, 42-47.

${ }^{4}$ B. A. Kairdolf, A. M. Smith, T. H. Stokes, M. D. Wang, A. N. Young, S. Nie. Semiconductor Quantum Dots for Bioimaging and Biodiagnostic Applications. Ann. Rev. Anal. Chem. 2013, 6, 143-162.

${ }^{5}$ M. Chen, M. Yin, Design and development of fluorescent nanostructures for bioimaging, Prog Polym Sci 2014, 39, 365-395.

${ }^{6}$ L. Cheng, C. Wang, Z. Liu, Upconversion nanoparticles and their composite nanostructures forbiomedical imaging and cancer therapy, Nanoscale 2013, 5, 23-37.

${ }^{7}$ G. Chen, H. Qiu, P. N. Prasad, X. Chen, Upconversion nanoparticles: design, nanochemistry, and applications in theranostics, Chem Rev 2014, 114, 5161-5214.

${ }^{8}$ Y.Y. Huang, M. Hamblin, A.C. H. Chen, 2009. Low-level laser therapy: an emerging clinical paradigm. SPIE Newsroom. http://dx.doi.org/10.1117/2.1200906.1669

${ }^{9}$ S. J. Matcher, M. Cope, and D. T. Delpy, In vivo measurements of the wavelength dependence of tissue scattering coefficients between 760 and $900 \mathrm{~nm}$ measured with time-resolved spectroscopy, APPLIED OPTICS, 1997, 36, 386-396.

${ }^{10}$ J.Q. Brown, T.M. Bydlon, L.M. Richards, et al., Optical assessment of tumor resection margins in the breast, IEEE J Sel Top Quantum Electron. 2010, 1, 16(3), 530-544.

${ }^{11}$ W. L. Byrne, A. DeLille, C. Kuo, J. S. de Jong, G. M. van Dam, K. P. Francis, M. Tangney, Use of optical imaging to progress novel therapeutics to the clinic, J. of Control. Release 172 (2013) 523-534.

${ }^{12}$ A. B. Alvero, D. Kim, E. Lima, N. J. Sumi, J. S. Lee, C. Cardenas, M. Pitruzzello, D.-A. Silasi, N. Buza, T. Fahmy, Gil Mor, Novel approach for the detection of intraperitoneal micrometastas is using an ovarian cancer mouse model, Sci Reports, 2017, 7:40989, DOI: 10.1038/srep40989

${ }^{13}$ H. Yukawa, M. Watanabe, N. Kaji, Y. Baba, Influence of Autofluorescence Derived From Living Body on In Vivo Fluorescence Imaging Using Quantum Dots, Cell Medicine, 2015, 7, 75-82.

${ }^{14}$ D. Jaque, C. Richard, B. Viana, K. Soga, X. Liu, J.G. Solé, Inorganic nanoparticles for optical bioimaging, Advances in Optics and Photonics, 2016, 8, 1-103.

${ }^{15}$ J. Hölsä, Persistent Luminescence Beats the Afterglow: 400 Years of Persistent Luminescence, The Electrochemical Society Interface, 2009, 42-45.

${ }^{16}$ S. H. D. Haddock, C. W. Dunn, P. R. Pugh, C. E. Schnitzler, Bioluminescent and Red-Fluorescent Lures in a Deep-Sea Siphonophore, Science 2005, 309, 263.

${ }^{17}$ J. Wang, Q. Ma, X.-X. Hu, H. Liu, W. Zheng, X. Chen, Q. Yuan, W. Tan, Autofluorescence-Free Targeted Tumor Imaging Based on Luminous Nanoparticles with Composition-Dependent Size and Persistent Luminescence, ACS Nano 2017, 11, 8010-8017.

${ }^{18}$ H.F. Brito, J. Holsa, T. Laamanen, M. Lastusaari, M. Malkamaki, L.C.V. Rodrigues, Persistent luminescence mechanisms: human imagination at work, Optical Materials Express, 2012, 2, 371-381.

${ }^{19}$ T. Matsuzawa, Y. Aoki, N. Takeuchi, Y. Murayama, New long phosphorescent phosphor with high brightness, $\mathrm{SrAl}_{2} \mathrm{O}_{4}: \mathrm{Eu}^{2+}, \mathrm{Dy}^{3+}$, Journal of the Electrochemical Society, 1996, 143, 2670-2673.

${ }^{20}$ C. Rosticher, B. Viana, M. A. Fortin, J. Lagueux, L. Faucher, Red Persistent luminescence and magnetic properties of nanomaterials for multimodal imaging. SPIE, Oxide-based Materials and Devices VI, OE108 2015 ${ }^{21}$ T. Maldiney, G. Sraiki, B. Viana, D. Gourier, C. Richard, D. Scherman, M. Bessodes, K. Van den Eeckhout, D. Poelman, and P. F. Smet, In vivo optical imaging with rare earth doped $\mathrm{Ca}_{2} \mathrm{Si}_{5} \mathrm{~N}_{8}$ persistent luminescence nanoparticles, Opt Mater Express 2012, 2, 261-268.

${ }^{22}$ P. Zeng, Wei, X. T.; Yin, M.; Chen, Y. H., Investigation of the long afterglow mechanism in $\mathrm{SrAl}_{2} \mathrm{O}_{4}: \mathrm{Eu}^{2+/} \mathrm{Dy}^{3+}$ by optically stimulated luminescence and thermoluminescence. Journal of Luminescence 2018, 199, 400-406

${ }^{23}$ Q. le Masne de Chermont, C. Chaneac, J. Seguin, F. Pelle, S. Maitrejean, J.-P. Jolivet, D. Gourier, M. Bessodes, D. Scherman, Nanoprobes with near-infrared persistent luminescence for in vivo imaging, Proceedings of the National Academy of Sciences of the United States of America, 2007, 104, 9266-9271.

${ }^{24}$ S.K. Sun, Wang, H. F.; Yan, X. P., Engineering Persistent Luminescence Nanoparticles for Biological Applications: From Biosensing/Bioimaging to Theranostics. Accounts ofChemical Research 2018, 51 (5), 1131 1143 
${ }^{25}$ T. Maldiney, A. Lecointre, B. Viana, A. Bessiere, M. Bessodes, D. Gourier, C. Richard, D. Scherman, Controlling Electron Trap Depth To Enhance Optical Properties of Persistent Luminescence Nanoparticles for In Vivo Imaging, Journal of the American Chemical Society, 2011, 133, 11810-11815.

${ }^{26}$ J.M. Liu, Liu, Y. Y.; Zhang, D. D.; Fang, G. Z.; Wang, S., Synthesis of GdAlO3:Mn4+,Ge4+@,Au Core-Shell Nanoprobes with Plasmon-Enhanced Near-Infrared Persistent Luminescence for in Vivo Trimodality Bioimaging. Acs Applied Materials \& Interfaces 2016, 8 (44), 29939-29949.

${ }^{27}$ J.M. Li, Wang, C. C.; Shi, J. P.; Li, P. H.; Yu, Z. F.; Zhang, H. W., Porous GdAlO3: Cr3+, Sm3+ drug carrier for real-time long afterglow and magnetic resonance dual-mode imaging. Journal of Luminescence 2018, 199, 363-371.

${ }^{28}$ T. Maldiney, A. Bessière, J. Seguin, E. Teston, S. K. Sharma, B. Viana, A. J.J. Bos, P. Dorenbos, M. Bessodes, D. Gourier, D. Scherman, C. Richard. The in vivo activation of persistent nanophosphors for the optical imaging of vascularization, tumors and grafted cells. Nature Materials 2014, 13, 418-426.

${ }^{29}$ F. Liu, W. Yan, Y.-J. Chuang, Z. Zhen, J. Xie, Z. Pan, Photostimulated near-infrared persistent luminescence as a new optical read-out from $\mathrm{Cr}^{3+}$-doped $\mathrm{LiGa}_{5} \mathrm{O}_{8}$, Scientific Reports 3, 1554, DOI:10.1038/srep01554

${ }^{30}$ Z.L. Xue, X.L. Li, Li, Y. B.; Jiang, M. Y.; Liu, H. R.; Zeng, S. J.; Hao, J. H., X-ray-Activated Near-Infrared Persistent Luminescent Probe for Deep-Tissue and Renewable in Vivo Bioimaging. ACS Applied Materials \& Interfaces 2017, 9 (27), 22132-22142.

${ }^{31}$ H.H. Liu, Ren, F.; Zhang, H.; Han, Y. B.; Qin, H. Z.; Zeng, J. F.; Wang, Y.; Sun, Q.; Li, Z.; Gao, M. Y., Oral administration of highly bright $\mathrm{Cr}^{3+}$ doped $\mathrm{ZnGa}_{2} \mathrm{O}_{4}$ nanocrystals for in vivo targeted imaging of orthotopic breast cancer. Journal of Materials Chemistry B 2018, 6 (10), 1508-1518.

${ }^{32}$ G. Ramirez-Garcia, Gutierrez-Granados, S.; Gallegos-Corona, M. A.; Palma-Tirado, L.; d'Orlye, F.; Varenne, A.; Mignet, N.; Richard, C.; Martinez-Alfaro, M., Long-term toxicological effects of pers istent luminescence nanoparticles after intravenous injection in mice. International Journal of Pharmaceutics 2017, 532 (2), 686-695.

${ }^{33}$ Y.Y. Liu, Liu, J. M.; Zhang, D. D.; Ge, K.; Wang, P. H.; Liu, H. L.; Fang, G. Z.; Wang, S., Persistent Luminescence Nanophosphor Involved Near-Infrared Optical Bioimaging for Investigation of Foodborne Probiotics Biodistribution in Vivo: A Proof-of-Concept Study. Journal of Agricultural and Food Chemistry 2017, 65 (37), 8229-8240.

${ }^{34}$ J. Wang, Li, J. L.; Yu, J. N.; Zhang, H. W.; Zhang, B. B., Large Hollow Cavity Luminous Nanoparticles with Near-Infrared Persistent Luminescence and Tunable Sizes for Tumor Afterglow Imaging and Chemo/Photodynamic Therapies. ACS Nano 2018, 12 (5), 4246-4258.

${ }^{35}$ T. Maldiney, Doan, B.-T.; Alloyeau, D.; Bessodes, M.; Scherman, D.; Richard, C., Gadolinium-Doped Persistent Nanophosphors as Versatile Tool for Multimodal In Vivo Imaging. Advanced Functional Materials 2015, 25 (2), 331-338.

${ }^{36}$ T. Maldiney, Ballet, B.; Bessodes, M.; Scherman, D.; Richard, C., Mesoporous persistent nanophosphors for in vivo optical bioimaging and drug-delivery. Nanoscale 2014, 6 (22), 13970-13976.

${ }^{37}$ E. Teston, Y. Lalatonne, D. Elgrabli , G. Autret, L. Motte, F. Gazeau , D. Scherman , O. Clément, C. Richard, T. Maldiney. Design, properties, and in vivo behavior of superparamagnetic persistent luminescence nanohybrids. Small 2015, 11, 2696-2704.

${ }^{38}$ E. Teston, Maldiney, T.; Marangon, I.; Volatron, J.; Lalatonne, Y.; Motte, L.; Boisson-Vidal, C.; Autret, G.; Clement, O.; Scherman, D.; Gazeau, F.; Richard, C., Nanohybrids with Magnetic and Persistent Luminescence Properties for Cell Labeling, Tracking, In Vivo Real-Time Imaging, and Magnetic Vectorization. Small 2018, 14 (16).

${ }^{39}$ R. Zou, Gong, S. M.; Shi, J. P.; Jiao, J.; Wong, K. L.; Zhang, H. W.; Wang, J.; Su, Q., Magnetic-NIR PersistentLuminescent Dual-Modal ZGOCS@MSNs@ $\mathrm{Gd}_{2} \mathrm{O}_{3}$ Core-Shell Nanoprobes For In Vivo Imaging. Chemistry of Materials 2017, 29 (9), 3938-3946.

${ }^{40}$ J. Shi, Sun, X.; Li, J.; Man, H.; Shen, J.; Yu, Y.; Zhang, H., Multifunctional near infrared-emitting longpersistence luminescent nanoprobes for drug delivery and targeted tumor imaging. Biomaterials 2015, 37, $260-$ 270.

${ }^{41}$ Y. Li, Zhou, S.; Dong, G.; Peng, M.; Wondraczek, L.; Qiu, J., Anti-Stokes Fluorescent Probe with Incoherent Excitation. Scientific Reports 2014, 4.

${ }^{42}$ J.M. Liu, Zhang, D. D.; Fang, G. Z.; Wang, S., Erythrocyte membrane bioinspired near-infrared persistent luminescence nanocarriers for in vivo long-circulating bioimaging and drug delivery. Biomaterials 2018, 165, 39-47.

${ }^{43}$ Y.J. Li, Yang, C. X.; Yan, X. P., Biomimetic Persistent Luminescent Nanoplatform for Autofluorescence-Free Metastasis Tracking and Chemophotodynamic Therapy. Analy tical Chemistry 2018, 90 (6), 4188-4195.

${ }^{44}$ J. Yang, Liu, Y. X.; Zhao, Y. Y.; Gong, Z.; Zhang, M.; Yan, D. T.; Zhu, H. C.; Liu, C. G.; Xu, C. S.; Zhang, H., Ratiometric Afterglow Nanothermometer for Simultaneous in Situ Bioimaging and Local Tissue Temperature Sensing. Chemistry of Materials 2017, 29 (19), 8119-8131. 
${ }^{45}$ Y. Li, Zhou, S.; Li, Y.; Sharafudeen, K.; Ma, Z.; Dong, G.; Peng, M.; Qiu, J., Long persistent and photostimulated luminescence in $\mathrm{Cr}^{3+-}$ doped $\mathrm{Zn}-\mathrm{Ga}-\mathrm{Sn}-\mathrm{O}$ phosphors for deep and reproducible tis sue imaging. Journal of Materials Chemistry C 2014, 2 (15), 2657-2663.

${ }^{46}$ A. Abdukayum, Chen, J.-T.; Zhao, Q.; Yan, X.-P., Functional Near Infrared-Emitting $\mathrm{Cr}^{3+} / \mathrm{Pr}^{3+} \mathrm{Co}-$ Doped Zinc Gallogermanate Persistent Luminescent Nanoparticles with Superlong Afterglow for in Vivo Targeted Bioimaging. Journal of the American Chemical Society 2013, 135 (38), 14125-14133.

${ }^{47}$ J. Li, Shi, J.; Shen, J.; Man, H.; Wang, M.; Zhang, H., Specific Recognition of Breast Cancer Cells In Vitro Using Near Infrared-Emitting Long-Persistence Luminescent $\mathrm{Zn}_{3} \mathrm{Ga}_{2} \mathrm{Ge}_{2} \mathrm{O}_{10}: \mathrm{Cr}^{3+}$ Nanoprobes. Nano-Micro Letters 2015, 7 (2), 138-145.

${ }^{48}$ F. Liu, Liang, Y.; Pan, Z., Detection of Up-converted Persistent Luminescence in the Near Infrared Emitted by the $\mathrm{Zn}_{3} \mathrm{Ga}_{2} \mathrm{GeO}_{8}: \mathrm{Cr}^{3+}, \mathrm{Yb}^{3+}, \mathrm{Er}^{3+}$ Phosphor. Physical Review Letters 2014, 113 (17).

${ }^{49}$ F. Liu, Yan, W.; Chuang, Y.-J.; Zhen, Z.; Xie, J.; Pan, Z., Photostimulated near-infrared persistent luminescence as a new optical read-out from $\mathrm{Cr} 3+$-doped $\mathrm{LiGa}_{5} \mathrm{O}_{8}$. Scientific Reports 2013, 3.

${ }^{50}$ X. Fu, Liu, C.; Shi, J.; Man, H.; Xu, J.; Zhang, H., Long persistent near infrared luminescence nanoprobes $\mathrm{LiGa}_{5} \mathrm{O}_{8}: \mathrm{Cr}^{3+}$-PEG-OCH${ }_{3}$ for in vivo imaging. Optical Materials 2014, 36 (11), 1792-1797.

${ }^{51}$ D. Chen, Chen, Y.; Lu, H.; Ji, Z., A Bifunctional $\mathrm{Cr} / \mathrm{Yb} / \mathrm{Tm}: \mathrm{Ca}_{3} \mathrm{Ga}_{2} \mathrm{Ge}_{3} \mathrm{O}_{12}$ Phosphor with Near-Infrared Long-Lasting Phosphorescence and Upconversion Luminescence. Inorganic Chemistry 2014, 53 (16), 86388645 .

${ }^{52}$ W.B. Dai, Lei, Y. F.; Zhou, J.; Xu, M.; Chu, L. L.; Li, L.; Zhao, P.; Zhang, Z. H., Near-infrared quantumcutting and long-persistent phosphor $\mathrm{Ca}_{3} \mathrm{Ga}_{2} \mathrm{Ge}_{3} \mathrm{O}_{12}: \mathrm{Pr}^{3+}, \mathrm{Yb}^{3+}$ for application in vivo bioimaging and dyesensitized solar cells. Journal of Alloys and Compounds 2017, 726, 230-239.

${ }^{53}$ J.P. Shi, Sun, X.; Zheng, S. H.; Li, J. L.; Fu, X. Y.; Zhang, H. W., A new near-infrared persistent luminescence nanoparticle as a multifunctional nanoplatform for multimodal imaging and cancer therapy. Biomaterials 2018, $152,15-23$.

${ }^{54}$ S. Kamimura, Xu, C.-N.; Yamada, H.; Terasaki, N.; Fujihala, M., Long-persistent luminescence in the nearinfrared from $\mathrm{Nd}^{3+-}$ doped $\mathrm{Sr}_{2} \mathrm{SnO}_{4}$ for in vivo optical imaging. Japanese Journal of Applied Physics 2014, 53 (9).

${ }^{55}$ Z. Li, Shi, J.; Zhang, H.; Sun, M., Highly controllable synthes is of near-infrared persistent luminescence $\mathrm{SiO}_{2} / \mathrm{CaMgSi}_{2} \mathrm{O}_{6}$ composite nanospheres for imaging in vivo. Optics Express 2014, 22 (9), 10509-10518.

${ }^{56}$ J. Xu, Murata, D.; Ueda, J.; Viana, B.; Tanabe, S., Toward Rechargeable Persistent Luminescence for the First and Third Biological Windows via Persistent Energy Transfer and Electron Trap Redistribution. Inorganic Chemistry 2018, 57 (9), 5194-5203.

${ }^{57}$ L.D. Hu, Wang, P. Y.; Zhao, M. Y.; Liu, L.; Zhou, L.; Li, B. H.; Albaqami, F. H.; El-Toni, A. M.; Li, X. M.; Xie, Y.; Sun, X. F.; Zhang, F., Near-infrared rechargeable "optical battery" implant for irradiation-free photodynamic therapy. Biomaterials 2018, 163, 154-162.

${ }^{58}$ H. Homayoni, Ma, L.; Zhang, J. Y.; Sahi, S. K.; Rashidi, L. H.; Bui, B.; Chen, W., Synthesis and conjugation of $\mathrm{Sr}_{2} \mathrm{MgSi}_{2} \mathrm{O}_{7}: \mathrm{Eu}^{2+}, \mathrm{Dy}^{3+}$ water soluble afterglow nanoparticles for photodynamic activation. Photodiagnos is and Photodynamic Therapy 2016, 16, 90-99.

${ }^{59}$ Z.Z. Yu, Liu, B.; Pan, W.; Zhang, T. T.; Tong, L. L.; Li, N.; Tang, B., A simple approach for glutathione functionalized persistent luminescence nanoparticles as versatile platforms for multiple in vivo applications. Chemical Communications 2018, 54 (28), 3504-3507.

${ }^{60}$ D.D. Zhan, Liu, J. M.; Song, N.; Liu, Y. Y.; Dang, M.; Fang, G. Z.; Wang, S., Fabrication of mesoporous $\mathrm{La}_{3} \mathrm{Ga}_{5} \mathrm{GeO}_{14}: \mathrm{Cr}^{3+}, \mathrm{Zn}^{2+}$ persistent luminescence nanocarriers with super-long afterglow for bioimaging-guided in vivo drug delivery to the gut. Journal of Materials Chemistry B 2018, 6 (10), 1479-1488.

${ }^{61}$ P.Q. Zhao, Ji, W.; Zhou, S. Y.; Qiu, L. H.; Li, L. F.; Qian, Z. Z.; Liu, X. M.; Zhang, H. L.; Cao, X. C., Upconverting and persistent luminescent nanocarriers for accurately imaging-guided photothermal therapy. Materials Science \& Engineering C-Materials for Biological Applications 2017, 79, 191-198.

${ }^{62}$ J.L. Li, Shi, J. P.; Wang, C. C.; Li, P. H.; Yu, Z. F.; Zhang, H. W., Five-nanometer $\mathrm{ZnSn}_{2} \mathrm{O}_{4}$ : Cr, Eu ultrasmall nanoparticles as new near infrared-emitting persistent luminescent nanoprobes for cellular and deep tissue imaging at $800 \mathrm{~nm}$. Nanoscale 2017, 9 (25), 8631-8638.

${ }^{63}$ S. Kamimura, Xu, C. N.; Yamada, H.; Marriott, G.; Hyodo, K.; Ohno, T., Near-infrared luminescence from double-perovskite $\mathrm{Sr}_{3} \mathrm{Sn}_{2} \mathrm{O}_{7}: \mathrm{Nd}^{3+}$ : A new class of probe for in vivo imaging in the second optical window of biological tissue. Journal of the Ceramic Society of Japan 2017, 125 (7), 591-595.

${ }^{64}$ K. Van den Eeckhout, D. Poelman, P.F. Smet, Persistent Luminescence in Non-Eu2+-Doped Compounds: A Review, Materials, 2013, 6, 2789-2818.

${ }^{65}$ K. Van den Eeckhout, P.F. Smet, D. Poelman, Persistent Luminescence in Eu2+-Doped Compounds: A Review, Materials, 2010, 3, 2536-2566.

${ }^{66}$ P. Smet in Persistent Phosphors, Chapter 274, Handbook on the Physics and Chemistry of Rare Earths, Vol. 48. http://dx.doi.org/10.1016/B978-0-444-63483-2.00001-6 (2015) 
${ }^{67}$ B. Viana, S. Sharma, D. Gourier, T. Maldiney, E. Teston, D. Scherman, C. Richard, Long term in vivo imaging with $\mathrm{Cr}^{3+}$ doped spinel nanoparticles exhibiting persistent luminescence, Journal of Lu minescence, 2016, 170, 879-887.

${ }^{68}$ S.K. Singh, Red and near infrared persistent luminescence nano-probes for bioimaging and targeting applications, RSC Advances, 2014, 4, 58674-58698.

${ }^{69}$ Y. Li, M. Gecevicius, J. Qiu, Long persistent phosphors: from fundamentals to applications, Chemical Society Reviews 2016, 45, 2090-2136.

${ }^{70}$ J. Holsa, T. Aitasalo, H. Jungner, M. Lastusaari, J. Niittykoski, G. Spano, Role of defect states in pers istent luminescence materials, Journal of Alloys and Compounds, 2004, 374, 56-59.

${ }^{71}$ C.R. Stanek, C. Jiang, S.K. Yadav, K.J. McClellan, B.P. Uberuaga, D.A. Andersson, M. Nikl, The effect of Ga-doping on the defect chemistry of $\mathrm{RE}_{3} \mathrm{Al}_{5} \mathrm{O}_{12}$ garnets, Physica Status Solidi B-Basic Solid State Physics, 2013, 250, 244-248.

${ }^{72}$ D. Gourier, A. Bessière, S. K. Sharma, L. Binet, B. Viana, N. Basavaraju, K. R. Priolkar, "Origin of the visible light induced persistent luminescence of $\mathrm{Cr}^{3+}$-doped zinc gallate,” J. Phys. Chem. Solids 2014, 75, 826837.

${ }^{73}$ A. Bessiere, S.K. Sharma, N. Basavaraju, K.R. Priolkar, L. Binet, B. Viana, A.J.J. Bos, T. Maldiney, C. Richard, D. Scherman, D. Gourier, Storage of Visible Light for Long-Lasting Phosphorescence in ChromiumDoped Zinc Gallate, Chemistry of Materials, 2014, 26, 1365-1373.

${ }^{74}$ Y. Zhuang, J. Ueda, S. Tanabe, P. Dorenbos, Band-gap variation and a self-redox effect induced by compositional deviation in $\mathrm{Zn}_{\mathrm{x}} \mathrm{Ga}_{2} \mathrm{O}_{3}+\mathrm{x}_{\mathrm{Cr}} \mathrm{Cr}^{3+}$ persistent phosphors, Journal of Materials Chemistry C, 2014, 2 , $5502-5509$.

${ }^{75}$ A. Bessiere, S. Jacquart, K. Priolkar, A. Lecointre, B. Viana, D. Gourier, $\mathrm{ZnGa}_{2} \mathrm{O}_{4}: \mathrm{Cr}^{3+}$ : a new red long-lasting phosphor with high brightness, Optics Express, 2011, 19, 10131-10137.

${ }^{76}$ S. Blahuta, A. Bessiere, B. Viana, V. Ouspenski, E. Mattmann, J. Lejay, D. Gourier, Defects Identification and Effects of Annealing on $\mathrm{Lu}_{2(1-\mathrm{x})} \mathrm{Y}_{2 \mathrm{x}} \mathrm{SiO}_{5}$ (LYSO) Single Crystals for Scintillation Application, Materials, 2011, 4, 1224-1237.

${ }^{77}$ C. Rosticher, B. Viana, T. Maldiney, C. Richard, C. Chaneac. Persistent luminescence of Eu, Mn, Dy doped calcium phosphates for in vivo optical imaging. Journal of Luminescence 2016, 170, 460-466.

${ }^{78}$ J. Ueda, K. Kuroishi, S. Tanabe, Development of blue excitable persistent phosphor of $\mathrm{Ce}^{3+}$-doped garnet ceramics by bandgap engineering and metal sensitization, Oxide-Based Materials and Devices V, 2014, 8987.

${ }^{79}$ Y. Katayama, T. Kayumi, J. Ueda, S. Tanabe, Enhanced persistent red luminescence in $\mathrm{Mn}^{2+}$-doped $(\mathrm{Mg}, \mathrm{Zn})$ $\mathrm{GeO}_{3}$ by electron trap and conduction band engineering, Optical Materials, 2018, 79, 147-151.

${ }^{80}$ P. Dorenbos, Lanthanide 4 f-electron binding energies and the nephelauxetic effect in wide band gap compounds, Journal of Luminescence, 2013, 136, 122-129.

${ }^{81} \mathrm{P}$. Dorenbos, Electronic structure and optical properties of the lanthanide activated $\mathrm{RE}_{3}\left(\mathrm{Al}_{1-\mathrm{x}} \mathrm{Ga}_{\mathrm{x}}\right)\left({ }_{5}\right) \mathrm{O}_{12}(\mathrm{RE}=$ Gd, Y, Lu) garnet compounds, Journal of Luminescence, 2013, 134, 310-318.

${ }^{82}$ Band-gap engineering for removing shallow traps in rare-earth Lu3A15O12 garnet scintillators using Ga3+ doping, By: Fasoli, M.; Vedda, A.; Nikl, M.; et al. PHYSICAL REVIEW B 2011, 84, 081102

${ }^{83}$ N. Kunkel, A.D. Sontakke, S. Kohaut, B. Viana, P. Dorenbos, Thermally Stimulated Luminescence and First Principle Study of Defect Configurations in the Perovskite-Type Hydrides $\mathrm{LiMH}_{3}: \mathrm{Eu}^{2+}(\mathrm{M}=\mathrm{Sr}, \mathrm{Ba})$ and the Corresponding Deuterides, The Journal of Physical Chemistry C, 2013, 120, 29414-29422.

${ }^{84}$ S.K. Sharma, A. Bessiere, N. Basavaraju, K.R. Priolkar, L. Binet, B. Viana, D. Gourier, Interplay between chromium content and lattice disorder on persistent luminescence of $\mathrm{ZnGa}_{2} \mathrm{O}_{4}: \mathrm{Cr}^{3+}$ for in vivo imaging, Journal of Luminescence, 2014, 155, 251-256.

${ }^{85}$ K. Korthout, K. Van den Eeckhout, J. Botterman, S. Nikitenko, D. Poelman, P.F. Smet, Luminescence and xray absorption measurements of persistent $\mathrm{SrAl}_{2} \mathrm{O}_{4}: \mathrm{Eu}$, Dy powders: Evidence for valence state changes, Physical Review B, 2011, 085140.

86 J. Ueda, S. Tanabe, T. Nakanishi, Analys is of $\mathrm{Ce}^{3+}$ luminescence quenching in solid solutions between $\mathrm{Y}_{3} \mathrm{Al}_{5} \mathrm{O}_{12}$ and $\mathrm{Y}_{3} \mathrm{Ga}_{5} \mathrm{O}_{12}$ by temperature dependence of photoconductivity measurement, Journal of Applied Physics, 2011, 110, 053102.

${ }^{87}$ A. Lecointre, A. Bessiere, A.J.J. Bos, P. Dorenbos, B. Viana, S. Jacquart, Designing a Red Pers istent Luminescence Phosphor: The Example of $\mathrm{YPO}_{4}: \mathrm{Pr}^{3+}, \operatorname{Ln}\left({ }^{3+}\right)(\mathrm{Ln}=\mathrm{Nd}$, Er, Ho, Dy), Journal of Physical Chemistry C, 2011, 115, 4217-4227.

${ }^{88}$ L. Casillas-Trujillo, D.A. Andersson, B. Dorado, M. Nikl, K.E. Sickafus, K.J. McClellan, C.R. Stanek, Intrinsic defects, nonstoichiometry, and aliovalent doping of $\left.\mathrm{A}^{\left({ }^{2+}\right.}\right) \mathrm{B}\left({ }^{4+}\right) \mathrm{O}_{3}$ perovskite scintillators, Physica Status Solidi B-Basic Solid State Physics, 2014, 251, 2279-2286.

${ }^{89}$ A. Bessiere, A. Lecointre, R.A. Benhamou, E. Suard, G. Wallez, B. Viana, How to induce red persistent luminescence in biocompatible $\mathrm{Ca}_{3}\left(\mathrm{PO}_{4}\right)(2)$, Journal of Materials Chemistry C, 2013, 1, 1252-1259; A.J.J. Bos, 
P. Dorenbos, A. Bessiere, B. Viana, Lanthanide energy levels in $\mathrm{YPO}_{4}$, Radiation Measurements, 2008, 43, $222-$ 226.

${ }^{90}$ K. Van den Eeckhout, A.J.J. Bos, D. Poelman, P.F. Smet, Revealing trap depth distributions in persistent phosphors, Physical Review B, 87 (2013

${ }^{91}$ Y.-J. Chuang, Z. Zhen, F. Zhang, F. Liu, J.P. Mishra, W. Tang, H. Chen, X. Huang, L. Wang, X. Chen, J. Xie, Z. Pan, Photostimulable Near-Infrared Persistent Luminescent Nanoprobes for Ultrasensitive and Longitudinal Deep-Tis sue Bio-Imaging, Theranostics, 2014, 4, 1112-1122.

${ }^{92}$ J. Botterman, K. Van den Eeckhout, I. De Baere, D. Poelman, P.F. Smet, Mechanoluminescence in $\mathrm{BaSi}_{2} \mathrm{O}_{2} \mathrm{~N}_{2}: \mathrm{Eu}$, Acta Materialia, 2012, 60, 5494-5500.

${ }^{93}$ R. Ngoune, A. Peters, D. von Elverfeldt, K. Winkler, G. Pütz, Accumulating nanoparticles by EPR: A route of no return, Journal of Controlled Release 2016, 238, 58-70.

${ }^{94}$ Y.-J. Chuang, Z. Zhen, F. Zhang, F. Liu, J.P. Mishra, W. Tang, H. Chen, X. Huang, L. Wang, X. Chen, J. Xie, Z. Pan, Photostimulable Near-Infrared Persistent Luminescent Nanoprobes for Ultrasensitive and Longitudinal Deep-Tissue Bio-Imaging, Theranostics, 4 (2014) 1112-1122.

${ }^{95}$ S.K. Sharma, D. Gourier, B. Viana, T. Maldiney, E. Teston, D. Scherman, C. Richard, Persistent luminescence of $\left.\left.\mathrm{AB}_{2}\right) \mathrm{O}_{4}\right): \mathrm{Cr}^{3+}(\mathrm{A}=\mathrm{Zn}, \mathrm{Mg}, \mathrm{B}=\mathrm{Ga}, \mathrm{Al})$ spinels: New biomarkers for in vivo imaging, Optical Materials, 2014, 36, 1901-1906.

${ }^{96}$ Y. Katayama, B. Viana, D. Gourier, J. Xu, S. Tanabe, Photostimulation induced persistent luminescence in $\mathrm{Y}_{3} \mathrm{Al}_{2} \mathrm{Ga}_{3} \mathrm{O}_{12}: \mathrm{Cr}^{3+}$, Optical Materials Express, 2016, 6, 1405-1413.

${ }^{97}$ F. Chen, Y. Liu, X. Liang, J. Wang, X. Bi, X. Wang and Z. Pan, A new up-conversion charging concept for effectively charging persistent phosphors using low-energy visible-light laser diodes, J. Mater. Chem. C, 2018, 6, 8003-8010.

${ }^{98}$ S.G.E. Bowman, R. Chen, Super-linear filling of traps in crystals due to competition during irradiation, , Journal of Luminescence, 1979, 18, 345-348.

${ }^{99}$ S.K. Sharma, D. Gourier, E. Teston, D. Scherman, C. Richard, B. Viana, Persistent luminescence induced by near infra-red photostimulation in chromium-doped zinc gallate for in vivo optical imaging, Optical Materials, 63 (2017) 51-58.

${ }^{100}$ D. Chen, Y. Chen, H. Lu, Z. Ji, A Bifunctional Cr/Yb/Tm: $\mathrm{Ca}_{3} \mathrm{Ga}_{2} \mathrm{Ge}_{3} \mathrm{O}_{12}$ Phosphor with Near-Infrared LongLasting Phosphorescence and Upconversion Luminescence, Inorganic Chemistry, 2014, 53, 8638-8645.

${ }^{101}$ F. Liu, Y. Liang, Z. Pan, Detection of Up-converted Persistent Luminescence in the Near Infrared Emitted by the $\mathrm{Zn}_{3} \mathrm{Ga}_{2} \mathrm{GeO}_{8}: \mathrm{Cr}^{3+}, \mathrm{Yb}^{3+}, \mathrm{Er}^{3+}$ Phosphor, Physical Review Letters, 2014, 113.

${ }^{102}$ F. Liu, Y. Chen, Y. Liang, Z. Pan, Phonon-assisted upconversion charging in $\mathrm{Zn}_{3} \mathrm{Ga}_{2} \mathrm{GeO}_{8}: \mathrm{Cr}^{3+}$ near-infrared persistent phosphor, Optics Letters, 2016, 41, 954-957.

${ }^{103}$ S. Liang, L. Pei-Pei, Y. Wen, L. Xia-Hui, L. Hong, C. Xiao-Feng, L. Gang, L. Juan, Y. Huang-Hao, LowDose X-ray Activation of W(VI)-Doped Persistent Luminescence Nanoparticles for Deep-Tissue Photodynamic Therapy, Advanced Functional Materials, 2018, 28, 1707496.

${ }^{104}$ Y. Zhuang, J. Ueda, S. Tanabe, Enhancement of red persistent luminescence in Cr3+-doped ZnGa2O4 phosphors by Bi2O3 codoping, Applied Physics Express, 2013, 6, 052602.

${ }^{105}$ P. Leblans, D. Vandenbroucke, P. Willems, Storage Phosphors for Medical Imaging, Materials, 2011, 4, 1034-1086.

106 A.M. Smith, M.C. Mancini, S. Nie, Second window for in vivo imaging, Nature Nanotechnology, 2009, 4, 710-711.

${ }^{107}$ T. Maldiney, M. Remond, M. Bessodes, D. Scherman, C. Richard, Controlling aminosilane layer thickness to extend the plasma half-life of stealth persistent luminescence nanoparticles in vivo. J of Mater Chem B, 2015, 3, 4009-4016.

${ }^{108}$ T. Maldiney, C. Richard, J. Seguin, N. Wattier, M. Bessodes, D. Scherman, Effect of core diameter, surface coating, and PEG chain length on the biodistribution of persistent luminescence nanoparticles in mice. ACS Nano 2011, 5, 854-862.

${ }^{109}$ G. Ramirez-Garcia, F. d'Orlye, S. Gutierrez-Granados, M. Martinez-Alfaro, N. Mignet, C. Richard, A. Varenne. Electrokinetic Hummel-Dreyer characterization of nanoparticle-plasma protein corona: The nonspecific interactions between PEG-modified persistent luminescence nanoparticles and albumin. Colloids and Surfaces, B: Biointerfaces 2017, 159, 437-444.

${ }^{110}$ G. Ramírez-García, F. d'Orlyé, S. Gutiérrez-Granados, M. Martínez-Alfaro, N. Mignet, C. Richard, A. Varenne, Functionalization and characterization of pers istent luminescence nanoparticles by dynamic light scattering, laser Doppler and capillary electrophoresis, Colloids and Surfaces B: Biointerfaces 2015, 136, 272281. 
${ }^{111}$ S. He, J. Song, J. Qu, Z. Cheng, Crucial breakthrough of second near-infrared biological window fluorophores: design and synthesis toward multimodal imaging and theranostics, 2018, DOI:

$10.1039 / \mathrm{c} 8 \mathrm{cs} 00234 \mathrm{~g}$.

${ }^{112}$ T. Lécuyer, E. Teston, G. Ramirez-Garcia, T. Maldiney, B. Viana, J. Seguin, N. Mignet, D. Scherman, C. Richard, Chemically engineered persistent luminescence nanoprobes for bioimaging, Theranostics 2016, 6, 2488-2524.

${ }^{113}$ C. Richard, Q. le Masne de Chermont, D. Scherman. Nanoparticles for imaging and tumor gene delivery. Tumori 2008, 94(2), 264-270.

${ }^{114}$ T. Maldiney, B. Viana, A. Bessiere, D. Gourier, M. Bessodes, D. Scherman, C. Richard. In vivo imaging with persistent luminescence silicate based nanoparticles. Optical Materials 2013, 35, 1852-1858.

${ }^{115}$ T. Maldiney, M. U. Kaikkonen, J. Seguin, Q. le Masne de Chermont, M. Bessodes, K. J. Airenne, S. YläHerttuala, D. Scherman, C. Richard. In vitro targeting of avidin-expressing glioma cells with biotinylated persistent luminescence nanoparticles. Bioconjugate Chemistry 2012, 23, 472-478.

${ }^{116}$ T. Maldiney, G. Byk, N. Wattier, J. Seguin, R. Khandadashe, M. Bessodes, C. Richard, D. Scherman. Synthes is and functionalization of persistent luminescence nanoparticles with small molecules and evaluation of their targeting ability. International Journal of Pharmaceutics 2012, 423, 102-107.

${ }^{117}$ Persistent and photostimulated red emission in $\mathrm{CaS}$ : Eu2+, Dy3+ nanophosphors, DC Rodríguez Burbano, SK Sharma, P Dorenbos, B Viana, et al. Advanced Optical Materials 3 (4), 551-557 (2015)

${ }^{118}$ A. Bessiere, S.K. Sharma, N. Basavaraju, K.R. Priolkar, L. Binet, B. Viana, A.J.J. Bos, T. Maldiney, C. Richard, D. Scherman, D. Gourier. Storage of visible light for long-lasting phosphorescence in chromium-doped zinc gallate. Chemistry of Materials 2014, 26, 1365-1373.

${ }^{119}$ S. K. Sharma, D. Gourier, B. Viana, T. Maldiney, E. Teston, D. Scherman, C. Richard.* Persistent luminescence in nanophosphors for long term in vivo bioimaging. Proceedings of SPIE 2015, Volume 9337, Nanoscale Imaging, Sensing, and Actuation for Biomedical Applications XII; 93370I; doi: 10.1117/12.2075585.

${ }^{120}$ T. Lecuyer, E. Teston, T. Maldiney, D. Scherman, C. Richard. Physico-chemical characterizations of Cr doped pers istent luminescence nanoparticles. SPIE BiOS, 2016, 97220X-97220X-8.

${ }^{121}$ M. Pellerin, E. Glais, T. Lecuyer, J. Xu, J. Seguin, S. Tanabe, C. Chanéac, B. Viana, C. Richard. $\mathrm{LaAlO}_{3}: \mathrm{Cr}^{3+}, \mathrm{Sm}^{3+}$ : nano-perovskite with persistent luminescence for in vivo optical imaging. J of Lumin, 2018, 202, 83-88.,

${ }^{122}$ B.B. Srivastava, A. Kuang, Y. Mao. Persistent luminescent sub-10 nm Cr doped $\mathrm{ZnGa}_{2} \mathrm{O}_{4}$ nanoparticles by a biphasic synthes is route. Chem. Commun. 2015, 51, 7372-7375.

${ }^{123}$ E. Teston, S. Richard, T. Maldiney et al. Non-Aqueous Sol-Gel Synthesis of Ultra Small Persistent Luminescence Nanoparticles for Near-Infrared In Vivo Imaging. Chem. Eur. J. 2015, 21, 7350-7354.

${ }^{124}$ Z. Li, Y. Zhang, X. Wu et al. Direct Aqueous-Phase Synthesis of Sub-10 nm "Luminous Pearls" with Enhanced in Vivo Renewable Near-Infrared Persistent Luminescence. J. Am. Chem. Soc. 2015, 137, 5304-5307. ${ }^{125}$ T. Ai, W. Shang, H. Yan, C. Zeng et al. Near infrared-emitting persistent luminescent nanoparticles for Hepatocellular Carcinoma imaging and luminescence-guided surgery. Biomaterials 2018, 167, 216-225.

${ }^{126}$ Y.J. Chuang, Z. Zhen, F. Zhang et al. Photostimulable Near-Infrared Persistent Luminescent Nanoprobes for Ultrasensitive and Longitudinal Deep-Tissue Bio-Imaging, Theranostics 2014, 4, 1112-1122.

${ }^{127}$ I. Canton, G. Battaglia, Endocytosis at the nanoscale, Chem. Soc. Rev. 2012, 41, 2718-2739.

${ }^{128}$ M. Janowski, J.W.M. Bulte, P. Walczak, Personalized nanomedicine advancements for stem cell tracking, Adv. Drug Delivery Rev. 2012, 64, 1488-1507.

${ }^{129}$ D. J. Naczynski, C. Sun, S. Tü rkcan, C. Jenkins, A.L. Koh, D. Ikeda, G. Pratx, L. Xing, X-ray-Induced Shortwave Infrared Biomedical Imaging Using Rare-Earth Nanoprobes, Nano Lett. 2015, 15, 96-102.

${ }^{130}$ H.Y. Chen, T. Moore, B. Qi, D.C. Colvin, E.K. Jelen, D.A. Hitchcock, J. He, O.T. Mefford, J.C. Gore, F. Alexis, J.N. Anker, Monitoring pH-Triggered Drug Release from Radioluminescent Nanocapsules with X-ray Excited Optical Luminescence, ACS Nano 2013, 7, 1178-1187.

${ }^{131}$ Z. Xue, X. Li, Y. Li, M. Jiang, G. Ren, H. Liu, S. Zeng, J. Hao, A 980 nm laser-activated upconverted persistent probe for NIR-to-NIR rechargeable in vivo bioimaging, Nanoscale, 2017, 9, 7276-7283.

${ }^{132}$ B. Zheng, Y. Bai, H. Chen, H. Pan, W. Ji, X. Gong, X. Wu, H. Wang, J. Chang, Near-infrared light excited upconverting persistent nanophosphors in vivo for imaging-guided cell therapy, ACS Appl. Mater. Interfaces, 2018 DOI: $10.1021 /$ acsami. 8 b05706.

${ }^{133}$ D.E. Lee, H. Koo, I.C. Sun et al. Multifunctional nanoparticles for multimodal imaging and theragnosis, Chem. Soc. Rev. 2012, 41, 2656-2672.

${ }^{134}$ H. Li, Bl. Harriss, A.Phinikaridou, S. Lacerda, G. Ramniceanu, BT. Doan, KL. Ho, CF. Chan, WS. Lo, RM. Botnar, R. Lan, C. Richard, GL. Law, NJ. Long, KL. Wong. Gadolinium and platinum in tandem: real-time multimodal monitoring of drug delivery by MRI and fluorescence imaging. Nanotheranostics 2017, 1(2), 186195. 
${ }^{135}$ R.L. Harivardhan, J.L. Arias, J. Nicolas et al. Magnetic Nanoparticles: Design and Characterization, Toxicity and Biocompatibility, Pharmaceutical and Biomedical Applications, Chem. Rev. 2012; 112, 5818-5878.

${ }^{136}$ A. Abdukayum, C.X.Yang, Q. Zhao et al. Gadolinium Complexes Functionalized Persistent Luminescent Nanoparticles as a Multimodal Probe for Near-Infrared Luminescence and Magnetic Resonance Imaging in Vivo, Anal. Chem. 2014, 86, 4096-4101.

${ }^{137}$ C. Tassa, S.Y. Shaw, R. Weissleder, Dextran-coated iron oxide nanoparticles: a versatile platform for targeted molecular imaging, molecular diagnostics, and therapy. Acc Chem Res 2011, 44, 842-852.

${ }^{138}$ Z. Fan, P.P. Fu, H. Yu, P. C. Ray, Theranostic nanomedicine for cancer detection and treatment, J. Food and Drug Anal 2014, 22, 3-17.

${ }^{139}$ T. Lammers, S. Aime, W.E. Hennink, G. Storm, F. Kiessling, Theranostic Nanomedicine, Acc. Chem. Res. 2011, 44, 1029-1038.

${ }^{140}$ S. M. Janib, A. S. Moses, J. A. MacKay, Imaging and drug delivery using theranostic nanoparticles, Adv. Drug Delivery Rev. 62 (2010) 1052-1063.

141 J. Xie, S. Lee, X. Chen, Nanoparticle-based theranostic agents, Adv. Drug Delivery Rev. 62 (2010) 10641079.

${ }^{142}$ Y. Zhang, H.F. Chan, K.W. Leong, Advanced materials and processing for drug delivery: The past and the future, Adv. Drug Delivery Rev. 2013, 65, 104-120.

${ }^{143}$ T. Asefa, Z. Tao, Biocompatibility of Mesoporous Silica Nanoparticles, Chem. Res. Toxicol., 2012, 25, 22652284.

${ }^{144}$ T. Maldiney, B. Ballet, M. Bessodes et al, Mesoporous persistent nanophosphors for in vivo optical bioimaging and drug delivery, Nanoscale, 2014, 6, 13970-13976.

${ }^{145}$ W. B. Dai, Y. F. Lei, S. Ye, E. H. Song, Z. Chena, Q. Y. Zhang, Mesoporous nanoparticles

$\mathrm{Gd}_{2} \mathrm{O}_{3} @ \mathrm{mSiO}_{2} / \mathrm{ZnGa}_{2} \mathrm{O}_{4}: \mathrm{Cr}^{3+}, \mathrm{Bi}^{3+}$ as multifunctional probes for bioimaging, J. Mater. Chem. B, 2016, 4, 18421852.

${ }^{146}$ Z. Huang, A Review of Progress in Clinical Photodynamic Therapy, Technol Cancer Res Treat 2005, 4, $283-$ 293.

${ }^{147}$ I. J. Mc Donald, T. J. Dougherty, Basic principles of photodynamic therapy, J. Porphyrins Phthalocyanines 2001, 5, 105-129.

${ }^{148}$ C.K. Lim, J. Heo, S. Shin, K. Jeong, Y.H. Seo, W.D. Jang, C.R. Park, S.Y. Park, S. Kim, I.C. Kwon, Cancer Lett. 2013, 334, 176-187.

${ }^{149}$ J.F. Lovell, T.W. Liu, J. Chen, G. Zheng, Chem. Rev. 2010, 110, 2839-2857.

150 C. Wang, L. Cheng, Z. Liu, Theranostics 2013, 3, 317-330.

${ }^{151}$ P. Agostinis, K. Berg, K.A. Cengel, T.H. Foster, A. Girotti, et al., Ca-Cancer J. Clin. 2011, 61, $250-281$.

152 S. B. Oh, H. R. Park, Y. J. Jang, S. Y. Choi, T. G. Son, J. Lee, Br. J. Pharmacol. 2013, 168, 421.

${ }^{153}$ K. Rothkamm, M. Lobrich, Proc. Natl. Acad. Sci. USA 2003, 100, 5057.

${ }^{154}$ G. Ramírez-García, M. Martínez-Alfaro, F. d'Orlyé, F. Bedioui, N. Mignet, A. Varenne, S. GutiérrezGranadosa, C. Richard, Photo-stimulation of persistent luminescence nanoparticles enhances cancer cells death, Int. J. of Pharm. 2017, 532, 696-703.

${ }^{155}$ H. Chen, G. D. Wang, Y.-J. Chuang, Z. Zhen, X. Chen, et al., Nanoscintillator-Mediated X- ray Inducible Photodynamic Therapy for In Vivo Cancer Treatment, Nano Lett. 2015, 15, 2249-2256.

${ }^{156}$ L. Song, P.-P. Li, W. Yang, X.-H. Lin, H. Liang, X.-F. Chen, G. Liu, J. Li, H.-H. Yang, Low-Dose X-ray Activation of W(VI)-Doped Persistent Luminescence Nanoparticles for Deep-Tissue Photodynamic Therapy, Adv. Funct. Mater. 2018, 1707496.

${ }^{157}$ J. Wang, J. Li, J. Yu, H. Zhang, B. Zhang, Large Hollow Cavity Luminous Nanoparticles with Near-Infrared Persistent Luminescence and Tunable Sizes for Tumor Afterglow Imaging and Chemo-/Photodynamic Therapies, ACS Nano 2018, DOI: 10.1021/acsnano.7b07606.

${ }^{158}$ L. Hu, P. Wang, M. Zhao, L. Liu, L. Zhou, B. Li et al., Near-infrared rechargeable "optical battery" implant for irradiation free photodynamic therapy, Biomaterials 2018, 163, 154-162.

${ }^{159}$ V. Shanmugam, S. Selvakumar, C.S. Yeh, Near-infrared light responsive nanomaterials in cancer therapeutics, Chem. Soc. Rev. 2014, 43, 6254-6287.

${ }^{160}$ J. Alander, T. Kaartinen, I. Laakso, T. Spillmann, T. Tuchin, V.V. Venermo, A review of indocyanine green fluorescent imaging in surgery, Int. J. Biomed. Imaging. 2012, 940585, doi:10.1155/2012/940585.

${ }^{161}$ E.I. Altinoğlu, T.J. Russin, J.M. Kaiser, B.M. Barth, P.C. Eklund, M. Kester, J.H. Adair, Near-infrared emitting fluorophore-doped calcium phosphate nanoparticles for in vivo imaging of human breast cancer, ACS Nano 2008, 2, 2075-2084.

${ }^{162}$ D.A. Jaffray, Image-guided radiotherapy: from current concept to future perspectives, Nat. Rev. Clin. Oncol. 2012, 9, 688-699. 
${ }^{163}$ H. Chen, B. Zheng, C. Liang, L. Zhao, Y. Zhanga, H. Pan,W. Ji, X. Gong, H. Wanga, J. Chang, Nearinfrared persistent luminescence phosphors $\mathrm{ZnGa}_{2} \mathrm{O}_{4}: \mathrm{Cr}^{3+}$ as an accurately tracker to photothermal therapy in vivo for visual treatment, Materials Science and Engineering C 2017, 79, 372-381.

${ }^{164}$ S. Naahidi, M. Jafari, F. Edalat, K. Raymond, A. Khademhosseini, Biocompatibility of engineered nanoparticles for drug delivery, J Control Release 2013, 166, 182-194.

${ }^{165}$ J. Lazarovits, Y. Y. Chen, E. A. Sykes, W. C. W. Chan, Nanoparticle-blood interactions: the implications on solid tumour targeting, Chem Comm 2015, 51, 2756-2767.

166 J. P. Mattos Almeida, A. L. Chen, A. Foster, R. Drezek, In vivo biodistribution of nanoparticles, Nanomedicine 2011, 6(5), 815-835.

${ }^{167}$ H. S. Choi, W. Liu, P. Misra, E. Tanaka, J. P. Zimmer, B. Itty Ipe, M. G Bawendi J. V. Frangioni, Renal clearance of quantum dots, Nat Biotechnol 2007, 25, 1165-1170.

${ }^{168}$ Y. N. Zhang, W. Poon, A. J. Tavares, I. D. McGilvray, W. C. W. Chan, Nanoparticle-liver interactions: cellular uptake and hepatobiliary elimination, J Control Release 2016, 240, 332-348.

${ }^{169}$ Kim M. Tsoi, Sonya A. MacParland, Xue-Zhong Ma, Vinzent N. Spetzler, Juan Echeverri et al, Mechanism of hard-nanomaterial clearance by the liver, Nat Mater 2016, 15, 1212-1221.

${ }^{170}$ A. S. Karakoti, S. Das, S. Thevuthasan, S. Seal, PEGylated Inorganic Nanoparticles, Angew. Chem. Int. Ed. 2011, 50, 1980-1994.

${ }^{171}$ K. Pombo García, K. Zarschler, L. Barbaro, J. A. Barreto, W. O’Malley, L. Spiccia, H. Stephan, B. Graham, Zwitterionic-Coated "Stealth" Nanoparticles for Biomedical Applications: Recent Advances in Countering Biomolecular Corona Formation and Uptake by the Mononuclear Phagocyte System, Small 2014, 10, 25162529.

${ }^{172}$ R. Zeineldin, M. Al-Haik, L. G. Hudson, Role of polyethylene glycol integrity in specific receptor targeting of carbon nanotubes to cancer cells, Nano Lett. 2009, 9, 751-757.

${ }^{173}$ S.-T. Yang, Y. Liu , Y.-W. Wang, A. Cao, Biosafety and Bioapplication of Nanomaterials by Designing Protein-Nanoparticle Interactions, Small 2013, 9, 1635-1653.

${ }^{174}$ Q. J. He, Z. W. Zhang, F. Gao, Y. P. Li and J. L. Shi, Small, 2011, 7, 271-280.

175 D. Tarn, C.E. Ashley, M. Xue, E.C. Carnes, J.I. Zink, C.J. Brinker, Mesoporous Silica Nanoparticle Nanocarriers: Biofunctionality and Biocompatibility, Acc. Chem. Res., 2013, 46, 792-801.

${ }^{176}$ Lu, M. Liong, Z. Li, J. I. Zink and F. Tamanoi, Small, 2010, 6, 1794-1805.

177 S. P. Hudson, R. F. Padera, R. Langer and D. S. Kohane, Biomaterials, 2008, 29, 4045-4055.

${ }^{178}$ D.T. Tu, W. Zheng, Y.S. Liu, et al. Luminescent biodetection based on lanthanide-doped inorganic nanoprobes, Coord Chem Rev, 2014, 273-274, 13-29.

${ }^{179}$ S. K. Sun, H.F. Wang, X.P. Yan, Engineering persistent luminescence nanoparticles for biological applications: From biosensing/bioimaging to theranostics, Accounts ofChemical Research 2018, 51, 1131-1143.

${ }^{180}$ Carlos D. S. Brites, Patricia P. Lima, Nuno J. O. Silva, Angel Millan,b Vitor S. Amaral, Fernando Palacio, and Luis D. Carlos, Thermometry at the nanoscale, Nanoscale, 2012, 4, 4799-4829.

${ }^{181}$ D. Jaque, F. Vetrone, Luminescence nanothermometry, Nanoscale 2012, 4, 4301-4326.

182 J. Yang, Y. Liu, Y. Zhao, Z. Gong, M. Zhang, D. Yan, et al, Ratiometric afterglow nanothermometer for simultaneous in situ bioimaging and local tis sue temperature sensing, Chem. Mater., 2017, 29, 8119-8131.

${ }^{183}$ E. Martın Rodriguez, G. Lopez-Pena, Eduardo Montes, G. Lifante, J. Garcia Sole, D. Jaque, et al., Pers istent luminescence nanothermometers, Appl Phys Lett 2017, 111, 081901.

${ }^{184}$ E. Glais, V. Dordevic, J. Papan, B. Viana, M. D. Dramicanin, $\mathrm{MgTiO}_{3}: \mathrm{Mn}^{4+}$ a multi-reading temperature nanoprobe, RSC Adv., 2018, 8, 18341-18346.

${ }^{185}$ K. Welsher, S.P. Sherlock, H. Dai H, Deep-tissue anatomical imaging of mice using carbon nanotube fluorophores in the second near-infrared window, Proc Natl Acad Sci USA 2011, 108, 8943-8948.

${ }^{186}$ O. T. Bruns, T. S. Bischof, D. K. Harris, D. Franke, Y. Shi et al, Next-generation in vivo optical imaging with short-wave infrared quantum dots, Nat Biomed Eng 2017, 1, 0056.

${ }^{187}$ S. He, J. Song, J. Qu, Z. Cheng, Crucial breakthrough of second near-infrared biological window fluorophores: design and synthesis toward multimodal imaging and theranostics, Chem Soc Rev 2018, DOI: $10.1039 / \mathrm{c} 8 \mathrm{cs} 00234 \mathrm{~g}$.

${ }^{188}$ E. Hemmer, A. Benayas, F. Légaré, F. Vetrone, Exploiting the biological windows: current perspectives on fluorescent bioprobes emitting above 1000 nm, Nanoscale Horiz., 2016, 1, 168-184.

${ }^{189}$ G. Hong, et al. Multifunctional in vivo vascularimaging using near-infrared II fluorescence. Nat. Med. 2012, $18,1841-1846$.

${ }^{190}$ G. Hong, et al. Through-skull fluorescence imaging of the brain in a new near-infrared window. Nat. Photon. $2014,8,723-730$. 
${ }^{191}$ J. Nie, Y. Li, S. Liu, Q. Chen, Q. Xu, J. Qiu, Tunable long persistent luminescence in the second near infrared window via crystal field control, Sci Reports 7, 12392, DOI:10.1038/s41598-017-12591-1.

192 J. Xu, S Tanabe, A. D. Sontakke, J. Ueda, Near-infrared multi-wavelengths long persistent luminescence of $\mathrm{Nd} 3+$ ion through persistent en ergy trans fer in $\mathrm{Ce}^{3+}, \mathrm{Cr}^{3+}$ co-doped $\mathrm{Y}_{3} \mathrm{Al}_{2} \mathrm{Ga}_{3} \mathrm{O}_{12}$ for the first and second bioimaging windows, Appl. Phys. Lett. 2015, 107, 081903/1-081903/4.

${ }^{193}$ J. Xu, D. Murata, J. Ueda, S. Tanabe, Near-infrared long persistent luminescence of $\mathrm{Er}^{3+}$ in garnet for the third bio-imaging window, Journal of Materials Chemistry C: Materials for Optical and Electronic Devices 2016 , 4, 11096-11103.

${ }^{194}$ M Pellerin, V Castaing, D Gourier, C Chanéac, B Viana, Persistent luminescence of transition metal (Co, $\mathrm{Ni}$...)-doped $\mathrm{ZnGa}_{2} \mathrm{O}_{4}$ phosphors for applications in the near-infrared range, Oxide-based Materials and Devices IX 10533, 1053321 (2018).

${ }^{195}$ Z. Xia,, Q. Liu, Progress in discovery and structuraldesign of color conversion phosphors for LEDs, Progr. in Mater. Sci. 2016, 84, 59-117.

${ }^{196}$ Z. Xia, K. R. Poeppelmeier, Chemistry-Inspired Adaptable Framework Structures, Acc. Chem. Res. 2017, 50, $1222-1230$. 